\title{
Overview of thermal ablation therapy for focal hepatic neoplasms
}

\section{S. Nahum Goldberg}

S. Nahum Goldberg M.D., "Overview of thermal ablation therapy for focal hepatic neoplasms," Proc. SPIE 10297, Matching the Energy Source to the Clinical Need: A Critical Review, 102970D (24 January 2000); doi: 10.1117/12.375214

SPIE. Event: Digital Optical Computing, 1990, Los Angeles, United States 


\title{
Overview of thermal ablation therapy for focal hepatic neoplasms
}

\author{
S. Nahum Goldberg MD \\ Minimally Invasive Therapies Laboratory, Department of Radiology, \\ Beth Israel Deaconess Medical Center, Boston, MA 02215
}

\begin{abstract}
Percutaneous image-guided ablative therapies using thermal energy sources such as radiofrequency, microwave, high intensity focused ultrasound, cryotherapy, and laser have received much recent attention as minimally-invasive strategies for the treatment of focal malignancy in the liver. Potential benefits of these techniques include the ability to ablate tumor in non-surgical candidates, reduced morbidity as compared to surgery, and the potential to perform the procedure on an outpatient basis. This article will present an overview of the principles and techniques used for thermal ablation, as well as review the results of published clinical trials.
\end{abstract}

Key words: thermal ablation, minimally-invasive therapy, radiofrequency, laser photocoagulation, microwaves, coagulation necrosis, high intensity ultrasound

\section{INTRODUCTION}

Advances in diagnostic imaging and fine needle biopsy technique have facilitated the development of percutaneous, image-guided therapies for the treatment of focal hepatic neoplasms $[1,2]$. The development of these new and "minimally-invasive" techniques has the potential to dramatically alter patient outcomes, since existing therapies either are associated with significant morbidity and mortality, or have limited efficacy. For example, hepatocellular carcinoma is often seen in the setting of hepatic cirrhosis, especially in high incidence areas such as Italy and the Far East. In these patients, liver dysfunction and associated coagulopathy combine to make surgical resection an unacceptably risky procedure. The development of in-situ ablative therapy using percutaneous ethanol instillation (PEI) has already provided an acceptable alternative to surgery for many of these patients $[3,4]$.

The rationale for local treatment of hepatic metastases is somewhat different, being based primarily on the success which has been achieved using a surgical approach. Without resection, for example, the prognosis for patients with hepatic metastases from colorectal carcinoma is dismal, with 5-year survival reported to be less than $1 \%$ and median survival estimated at 9.6 months [5]. Unfortunately, systemic chemotherapy has been relatively unsuccessful in significantly improving patient outcomes, with the result that

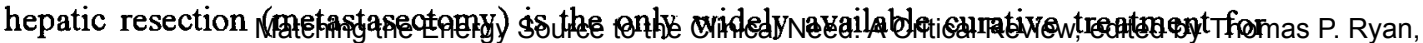


these patients. Recent reports, most notably a large multi-institutional study involving 859 patients treated at 24 institutions and others [6-11], have documented 5-year survivals of $25-90 \%$ following the resection of 4 or fewer hepatic metastases. Some of these reports may have been overly optimistic, however, most authors now believe that $30-35 \% 5$-year survival can be achieved with proper patient selection [12-14]. However, despite its success in improving overall patient survival, metastasectomy is associated with significant morbidity, as well as a perioperative mortality rate of $2-10 \%$ [5-14]. Furthermore, only a small fraction of patients with hepatic metastases can actually undergo metastasectomy as they are either deemed poor surgical risks, or the number and distribution of their tumors does not permit complete resection while at the same time leaving behind an adequate volume of normal liver to support life. Nevertheless, the success of hepatic metastasectomy in certain patients has lead many investigators to speculate that similar results might be obtained with an effective in-situ ablative technique. In addition, because it would be less invasive than surgical resection, such a technique could be applicable to many patients who would not be considered for metastasectomy.

Percutaneous image-guided therapies for hepatic neoplasms can be divided into two broad categories: 1) direct intra-tumoral injection of compounds such as ethanol, hot saline, and acetic acid in an attempt to induce cellular death, and 2) thermally mediated techniques such as radiofrequency ablation (RF), interstitial laser photocoagulation (ILP), microwave therapy, or cryotherapy. An additional transcutaneous ablative technique, high-intensity focal ultrasound (HIFU) has been used with limited success in organs other than the liver, but may ultimately have a role in the treatment of hepatic lesions if certain limitations can be overcome.

While the clinical efficacy of some of these techniques (such as percutaneous ethanol instillation (PEI) for the treatment of hepatocellular carcinoma) has been clearly established, experience with the remainder (i.e., thermal ablation using energy sources) is considerably more preliminary, and an assessment of their safety and efficacy cannot be adequately performed until the results of additional clinical trials are available. Many of these percutaneous techniques involve nascent, but rapidly developing technologies, where innovations are occurring at a rapid pace, and published results may not fully represent the "state-of-the-art". In this review, we will describe each of the techniques for thermal ablation including radiofrequency (RF), laser, microwave, ultrasound, and cryotherapy; and present preliminary laboratory and/or clinical data, as available. The role of injection therapies such as PEI, and other minimally-invasive therapies such as chemoembolization are, for the most part, bey ond the scope of this article.

\section{OVERVIEW OF THERMAL ABLATION THERAPY}

The main aim of thermal tumor ablation therapy is to destroy an entire tumor using heat to kill the malignant cells in a minimally invasive fashion without damaging adjacent vital structures. This often includes the treatment of a 0.5 to $1 \mathrm{~cm}$ margin of apparently normal liver tissue adjacent to the lesion in order to eliminate microscopic foci of disease and the uncertainty which often exists regarding the precise location of actual tumor margins. Therefore, it is necessary to understand how heat interacts with malignant and benign tissue to induce cell death. 
Cellular homeostasis can be maintained with mild elevation of temperature to approximately $40^{\circ} \mathrm{C}$. When temperatures are increased to $42-45^{\circ} \mathrm{C}$ (hyperthermia), cells become more susceptible to damage by other agents such as chemotherapy and radiation $[15,16]$. However, even prolonged heating at these temperatures will not kill all cells within a given volume, as continued cellular functioning and tumor growth can be observed following relatively long exposure to these temperatures. When temperatures are increased to $46^{\circ} \mathrm{C}$ for 60 minutes, irreversible cellular damage occurs [17]. Increasing the temperature only several degrees to $50-52^{\circ} \mathrm{C}$ markedly shortens the time necessary to induce cytotoxicity (4-6 minutes) [18]. Between $60-100^{\circ} \mathrm{C}$, there is near instantaneous induction of protein coagulation which irreversibly damages key cytosolic and mitochondrial enzymes, as well as nucleic acid - histone protein complexes $[19,20]$. Cells experiencing this extent of thermal damage most often, but not always, undergo coagulative necrosis over the course of several days. The term "coagulation necrosis" has therefore been used to denote irreversible thermal damage to cells whether or not the ultimate manifestations of cell death fulfill the strict histologic criteria of coagulative necrosis. Temperatures greater than $105^{\circ} \mathrm{C}$ result in tissue boiling, vaporization, and carbonization. These processes usually retard optimal ablation due to a resultant decrease in energy transmission [18]. Thus, a key aim for ablative therapies is achieving and maintaining a $50-100^{\circ} \mathrm{C}$ temperature range throughout the entire target volume.

\subsection{Sources of thermal energy}

It is important to remember that tumor cells can be equally effectively be destroyed by cytotoxic heat from different sources. As long as adequate heat can be generated throughout the tumor volume, we will accomplish our objective of eradicating the tumor. Multiple energy sources have been used to provide the heat necessary to induce coagulation necrosis. Electromagnetic energy has been used in the form of both radiofrequency and microwaves $[21,22]$. Photocoagulation uses intense pulses of light produced by a laser as the energy source $[23,24]$. In a similar vein, high intensity focused ultrasound uses sound energy to produce heat [25]. Additionally, direct injection of heated fluids including saline, ethanol, and contrast has been used to induce coagulation by direct thermal contact [26].

For most methods of thermal ablation, energy has been applied percutaneously using needle-shaped applicators. These high doses of energy usually concentrate around the applicator and require heat conduction through the tissue from this local thermal reservoir to coagulate deeper tissues. For RF, radio waves emanate from the noninsulated distal portion of the electrode. Heat is produce by resistive forces (i.e., ionic agitation) surrounding the electrode as the current flows to ground, usually a foil pad attached to the patient's back or thighs. For microwave, needle shaped electrodes function as an antenna which concentrates energy about the applicator. Polar molecules in the tissue attempt to align with the electromagnetic field vectors. This rapid molecular movement is resisted by friction which induces heating the tissue. For photocoagulation, thin optical fibers which conduct laser energy are placed through needles which are positioned in the tumor. These bare fibers transmit the intense light into the tissue where it is converted into heat. For both microwave and laser, the depth of energy penetration can be altered by altering the frequency of the energy source. Percutaneous probes containing multiple small piezoelectric transducers can deposit sufficient sound energy to 
heat adjacent tissues. Another potential application of ultrasound energy has been incorporated into extracorporeal systems of energy delivery. These rely on focusing of intense energy from an external ultrasound source. Unfortunately, the maximum size for a single ablative focus has thus far approximated a grain of rice and therefore complex image-guided systems are necessary to adequately treat larger areas [25]. However, improvements in technology may ultimately allow for the treatment of larger foci.

\subsection{Heat-tissue interactions}

To adequately destroy an entire tumor, the entire lesion must be subject to cytotoxic temperatures. However, there are multiple and often tissue specific limitations which prevent heating of the entire tumor volume. Most importantly, there is heterogeneity of heat distribution throughout a given lesion to be treated. For all percutaneous methods, heat deposition is greatest surrounding the probe with less heat deposited deeper in the tissues. This is caused by both a rapid fall-off of energy away from the applicator, as well as poor heat conduction within the tissues. Additionally, the total quantity of energy which can be deposited into the tissues is limited by tissue boiling and vaporization at extreme temperatures $\left(105^{\circ} \mathrm{C}\right)$. When tissue vaporization occurs gas is formed. For all methods, this gas serves as an insulator which prevents heat spread. Additionally, for RF gas formation increases tissue impedance which prevents deposition of heating current. Thus, energy deposition using a single applicator (i.e., a monopolar RF electrode or a single laser fiber) produces coagulation measuring only up to $1.6 \mathrm{~cm}$ in diameter [27 30].

Several strategies have been developed in an attempt to improve tissue - energy interactions for thermal ablation therapy with the goal of increasing the region of induced coagulation to enable the treatment of most clinically relevant tumors (i.e., those measuring greater than $1-2 \mathrm{~cm}$ in diameter). These can be classified as strategies which permit an increase in overall energy (amount and rate) deposited, strategies which improve heat conduction within the tissue, and strategies which decrease tumor tolerance to heat.

\subsubsection{Increasing energy deposition}

A common method for increasing energy deposition throughout an entire lesion has been to repeatedly insert multiple $\mathrm{RF}$, laser, and microwave probes into the tissue to increase the diameter of induced coagulation [31 - 34]. This approach, however, is both time consuming and difficult to employ in the clinical setting particularly because multiple overlapping treatments must be performed in a contiguous fashion (in all three dimensions) to destroy the entire lesion. Simultaneous application of energy using arrays can reduce the duration of therapy [35 - 36]. However, the precise positioning of multiple probes can also be technically challenging. The development of umbrella RF electrodes with multiple hooked arrays have overcome some of these problems and have enabled the creation of larger foci of coagulation [31, 37 - 39].

Much recent development has centered on strategies which preferentially cool tissues nearest the probe in an attempt to increase overall energy deposition. Internally-cooled electrodes have been used with radiofrequency, microwave, high intensity ultrasound, and laser [40 - 44]. For internally-cooled devices, two internal lumens permit the delivery of chilled perfusate to the tip of the electrode, and the warmed effluent to be 
removed to a collection unit outside of the body. This causes a heat sink effect which removes heat closest to the electrode. Pulsing of energy is another strategy that has been used with RF and laser to increase the mean intensity of energy deposited. When pulsing is used, periods of high energy deposition are rapidly altemated with periods of low energy deposition. If a proper balance between high and low energy deposition is achieved, preferential tissue cooling occurs adjacent to the applicator during periods of minimal energy deposition without significantly decreasing heating deeper in the tissue. Thus, even greater energy can be applied during periods of high energy deposition thereby enabling deeper heat penetration and greater tissue coagulation $[44,45]$. Combination of both internal-cooling and pulsing has been demonstrated as synergistic with even greater tissue destruction observed than either method alone [46].

\subsubsection{Improved tissue heat conduction}

Improved heat conduction within the tissues by injection of saline and other compounds has also been proposed [ $48-50]$. The heated liquid spreads thermal energy farther and faster than heat conduction in normal "solid" tissue. An additional potential benefit of simultaneous saline injection with $R F$ or microwave is that it increases tissue conductivity thereby enabling greater current flow. Similarly, amplification of current shifts using iron compounds, injected or deposited in the tissues prior to ablation have been used for RF and microwave [49].

Another primary factor which can alter the extent of coagulation necrosis is tissue composition, as heat conducts through different tissues at various rates $[50,51]$. For example, poor thermal conduction has been documented for bone compared to muscle [51]. This has been used as an advantage in the treatment of hepatocellular carcinomas and vertebral body lesions. Livraghi et al. have described the "oven effect" in which cirrhotic tissue insulates $\mathrm{HCC}$ nodules, thereby increasing temperatures within the targeted tumor during RF therapy [50]. Dupuy et al. [51] have shown that cortical bone also serves as an insulator thereby enabling treatment of vertebral body lesions without damaging the spinal cord.

\subsection{Strategies which decrease tumor tolerance to heat}

Several investigators have demonstrated experimentally the relationship between blood flow and the extent of coagulation induced by RF ablation in normal tissues and human intrahepatic tumors [52 - 56]. Computer modeling of the Bio-heat equation demonstrates that for a given tissue and power deposition, the effects of tissue blood flow predominate [56]. Empirically, RF-induced coagulation necrosis has been more limited and variable in-vivo, particularly in clinical practice, as compared to the reproducible results obtainable in ex-vivo tissues. Coagulation necrosis in-vivo is also often shaped by the presence of hepatic vasculature in the vicinity of the ablation [52]. Furthermore, experiments altering hepatic perfusion by mechanical or pharmacological means during thermal ablation of normal liver and tumors strongly support the contention that perfusion-mediated tissue cooling is largely responsible for this reduction in observed coagulation [52 - 53]. A tight correlation between the diameter of RF induced coagulation and pharmacologically modulated blood flow in normal liver has also been demonstrated [53]. Recently, Patterson et al. have confirmed the strong predictive nature of hepatic blood flow on the extent of RF induced coagulation in normal in-vivo porcine liver using a hooked electrode system [54]. Coagulation created by RF power during 
vascular inflow occlusion was significantly larger than coagulation created with normal blood flow ( $\left.35.0 \mathrm{~cm}^{3} \mathrm{vs} 6.5 \mathrm{~cm}^{3} ; \mathrm{p}<0.001\right)$. Additionally, the number of blood vessels within a $1-\mathrm{cm}$ radius of the electrode, strongly predicted minimum lesion diameter and lesion volume. Thus, for in-vivo tissues, a heat-sink effect from flowing blood likely limits the extent of tissue in which the necessary cytotoxic temperatures to induce coagulation can be achieved. Thus, in in-vivo tissues a heat-sink effect likely prevents achieving the cytotoxic temperature necessary to induce coagulation $\left(50-60^{\circ} \mathrm{C}\right)$ in highly vascular regions of a tumor (i.e., the peripheral tumor - parenchyma interface).

On the basis of these observations, several strategies for reducing blood flow during ablation therapy have been proposed. Total portal inflow occlusion (Pringle maneuver) has been used at open laparotomy [52]. Angiographic balloon occlusion can be used, but may not prove adequate for intrahepatic ablation given the dual hepatic blood supply with redirection of compensated flow [52]. Embolotherapy prior to ablation with particulates that occlude sinusoids such as gel-foam or lipoidol may overcome this limitation [57]. Pharmacologic modulation of blood flow and anti-angiogenesis therapy are theoretically possible, but should currently be considered experimental. Additional strategies that decrease tumor tolerance to heat have been proposed, but as of yet are not well studied. Theoretically, previous insult to the tumor cells by cellular hypoxia (caused by vascular occlusion or antiangiogenesis factor therapy [i.e., endostatin], or prior tumor cell damage from chemotherapy or radiation could be used to increase tumor sensitivity to heat. Synergy between chemotherapeutic agents and hyperthermic temperatures $\left(42-45^{\circ} \mathrm{C}\right)$ has already been established [15 - 16].

\section{DIAGNOSTIC IMAGING FOR THERMAL ABLATION THERAPY}

Diagnostic imaging applications can be thought of as accomplishing three distinct tasks for thermal ablation procedures. These include targeting of the lesion to be treated (i.e., ensuring optimal positioning of the energy applicator during ablation); guidance for energy deposition for the duration of the treatment plan; and assessment of results at follow-up. The imaging appearances for laser, microwave, and RF are remarkably similar for any given organ and degree of tissue heating. Needle-like applicators will all look approximately the same for any given modality, and coagulation (or heated) tissues should theoretically appear identical for a given extent of coagulation, regardless of how it was induced.

\subsection{Diagnostic imaging for lesion targeting}

Multiple imaging modalities (sonography, CT, and MR Imaging) can be used to guide the percutaneous placement of thermal energy applicators into the selected target $[1,2]$. Because in most cases adequate lesion conspicuity and visualization of the applicator can be achieved with any of these methods, the decision as to which imaging modality is selected has often been dictated by personal preference or research interests. Most image-guided thermal ablation procedures have thus far been performed using ultrasonography. Benefits touted for sonography include the real-time visualization of applicator placement, the portability of the technology, nearly universal availability, cost, and the ability to target and guide ablation therapy using intracavitary, endoluminal transducers (i.e., for transrectal or transgastric energy application to the prostate or 
abdominal organs). Limitations of sonography include occasional poor lesion visualization due to a lack of innate tissue conspicuity or overlying bone or gas containing structures. MR imaging generally provides greatest tumor-to-tissue conspicuity and the ability to use multiplanar guidance. However, this technology is relatively expensive, requires specialized ablation equipment that is compatible with a high magnetic field, and is the least available for general clinical use. CT, and more recently real-time CT fluoroscopy, have also been used to ensure adequate positioning of the energy applicator. Though these techniques have not yet been extensively evaluated (i.e., CT fluoroscopy) it is fair to say that CT falls between ultrasound and MR with respect to cost, tissue contrast, and complexity. In our clinical practice, we use a combined approach of CT fluoroscopy and sonography at the same setting to document optimal RF electrode positioning.

\subsection{Diagnostic imaging to guide therapy}

In order to prevent under or over treatment of a lesion, it is essential to have accurate and reliable methods for determining the adequacy of therapy. Thus, there is significant ongoing investigation into the development of imaging strategies which enable rapid assessment of the extent of tissue destruction induced by thermal ablation. Despite initial enthusiasm, gray-scale sonographic findings observed during the thermal ablation procedure are not sufficiently accurate in predicting the extent of coagulation to guide thermal therapy $[33,53,58,59]$. The progressively increasing hyperechogenic focus which is often seen surrounding the distal portion of the applicator during the application of energy has been found to represent microbubbles of gas which form in the heated tissue and does not represent tissue coagulation [60]. This hyperechogenic region can be variable in size, quite irregular in shape and contour, and often demonstrates complete resolution within one hour of ablation. Additionally, this intense echogenicity can often obscure the energy applicator and tumor, increasing the difficulty of repositioning for further treatment.

Conventional color-flow and power-Doppler sonography have similarly not been found useful in assessing the extent of induced coagulation [33, 58]. However, in one study contrast-enhanced color-Doppler sonography using a synthetic microbubble ultrasound contrast agent was able to achieve $92 \%$ accuracy in predicting the extent of coagulation in VX2 rabbit tumors immediately following RF ablation [61]. Additionally, sonographic contrast has been used to direct repeat energy application to residual enhancing (and presumably viable) foci within the treatment zone [62].

For solid organs such as the liver, unenhanced CT scans obtained immediately after ablation often reveal increased density at the center of the treatment zone which is most often surrounded by a region of hypoattenuation [31 - 33, 59,63-65]. With the exception of encapsulated lesions such as hepatocellular carcinomas, the margins of this outer hypodense zone are often too diffuse to be of sufficient sensitivity to assess therapy. However, contrast-enhanced CT is quite useful in discriminating between ablated and residual, viable tumor immediately after thermal ablation as it demonstrates regions of hypoattenuation devoid of characteristic tumorous or parenchymal enhancement in treated portions of the tumor. For intrahepatic metastases, the differentiation of coagulation necrosis from hypoattenuating tumor is usually easiest on images in the equilibrium phase of contrast enhancement (5 - $10 \mathrm{~min}$ after iodinated contrast administration), where persistent hypoattenuation is seen in coagulated tissues, but not in 
viable tumor [19]. Hepatic arterial phase images are most useful for early enhancing hepatocellular carcinomas. Imaging during the hepatic arterial phase can also demonstrate a thin rim of contrast which corresponds at pathology to an early inflammatory reaction to the thermal damage. This inflammatory rim can be seen immediately following ablation, and often regresses over the first month following treatment.

MR images characteristically reveal altered signal on both T1- and T2-weighted images $[59,66,69]$. Treated areas are devoid of gadolinium enhancement. Several studies have documented the particular utility of decreased signal on T-2 weighted images as a marker for induced coagulation $[67,69]$. Radiologic-pathologic correlation in both experimental and clinical studies have demonstrated that $\mathrm{CT}$ and $\mathrm{MR}$ imaging findings predict the region of coagulation to within $2-3 \mathrm{~mm}$ [19].

One key advantage of MR over other diagnostic imaging modalities is its potential ability to aid in determining the extent of coagulation during energy application. Heat sensitive sequences have been constructed and permit tailoring of energy deposition [70 - 73]. Such a strategy is most useful in allowing the operator to limit energy deposition when heating adjacent to a critical structure (i.e., nerves) reaches cytoxic temperatures. Pulsing switches have been developed to overcome interference of radiofrequency and microwave usage during the acquistion of MR radiofrequency encoded data [73].

\subsection{Long-term imaging follow-up}

Although initial imaging can serve as a good indication toward the adequacy of therapy, the resolution and accuracy of current imaging modalities preclude identification of residual microscopic foci of malignancy, particularly at the periphery of a treated lesion (where blood flow is greatest). These viable tumor foci will inevitably continue to grow and if untreated will result in failed therapy. Additionally, we have not found the use of needle biopsy helpful given issues of sampling error, and the possible difficulty in differentiating between adequately treated and viable tumor using histopathologic techniques alone. Thus, long term imaging follow-up is necessary to find untreated regions of the tumor or document complete treatment of a given focal malignancy.

Long term follow-up of thermal ablation using ultrasonography has limited value [58]. Obscuration of the characteristic peri-tumoral halo observed pre-treatment is often observed, and the variability of gray-scale sonographic changes precludes accurate assessment of induced coagulation. Recently, however, it has been demonstrated that sonographic, microbubble blood pool agents such as SH 508 A (Levovist; Schering AG, Berlin, Germany) may be helpful in differentiating treated tumor from the avascular coagulation at follow-up to 6 months [74].

Contrast-enhanced CT has been the mainstay of long-term imaging follow-up. Coagulated, non-enhancing regions increase in conspicuity and develop sharper margins by two weeks post-ablation $[19,59]$. Imaging at $6-12$ months can demonstrate marked regression of the metastasis and the region of induced coagulation necrosis. Most commonly, the non-enhancing treatment focus shrinks less than $20 \%$ in volume. A peripheral rim that densely enhances on delayed contrast images often surrounds the region of coagulation. This finding should not be misconstrued as residual tumor, as experimental and clinical studies have demonstrated this to represent inflammatory 
reaction to the thermally damaged cells [59]. A bulky, irregular rim at the edge of a treatment site is the most common appearance of an incompletely treated lesion.

When using MR for long-term follow-up (exceeding 3 months), we have relied primarily on the presence or absence of gadolinium enhancement within the treated region $[58,59]$. In contrast to MR images obtained within three days of ablation, we have observed heterogeneous alteration on un-enhanced $\mathrm{T} 1$ - and T2-weighted images. This changing variability in signal intensity throughout the ablated region is likely caused by an uneven evolution of the necrotic area and the host response to thermal damage. Hence, these images have therefore been thus far too variable to be relied upon as adequate proof of tumor destruction. Furthermore, the multiplicity of potential imaging sequences and parameters used for MR imaging has only further compounded this problem. Further research may ultimately lead to greater insight into the biologic mechanisms that account for such signal heterogeneity. For gadolinium enhanced images, it is also common to detect a thin rim of enhancement after treatment. As for CT, only when this rim appears bulky is this finding to be interpreted as representing untreated tumor.

Nuclear medicine has been used in a limited number of cases following ablation therapy. In one study, positron emission tomography scanning with 18-Fluoro-Deoxy-Glucose (18-FDG) was used to detect active foci of residual tumor following percutaneous ethanol instillation in intrahepatic metastases [75].

Our current imaging strategy following thermal ablation includes an initial contrastenhanced CT or MR study on the day of treatment to determine whether the patient has residual gross, viable disease that necessitates immediate retreatment. Follow - up imaging is then performed at 1 and 3 months, and every $3-4$ months thereafter. These scans are helpful in documenting the presence or absence of residual tumor, which often may be amenable to additional thermal ablation treatments. If there is no evidence of peripheral tumor regrowth by $6-12$ months, adequate treatment can be inferred.

\section{CLINICAL TECHNIQUES AND RESULTS}

\subsection{RADIOFREQUENCY ABLATION}

Liver tumor ablation can be accomplished using radiofrequency to induce thermally mediated coagulation necrosis [1-2]. Both monopolar and bipolar radiofrequency generators have been used, and several generators are commercially available, some of which have incorporated circuitry which enables measurement of generator output (wattage and milliamperage), tissue impedance, and electrode tip temperature.

Radiofrequency energy is delivered to the tumor by means of an RF electrode, a thin (usually 21-14 gauge) needle which is electrically insulated along all but the distal $1-3 \mathrm{~cm}$ of the shaft. This needle is placed into the tumor using a percutaneous approach. When connected to the appropriate generator, radiofrequency current flows from the exposed, non-insulated portion of the electrode. As this current flows to electrical ground, it results in ion agitation, and is converted into heat, which induces cellular death via 
coagulation necrosis [21]. For monopolar systems the ground is usually a pad placed on the patient's back or thigh, while in bipolar systems, a second electrode serves as the ground. Sesquipolar systems use an active electrode smaller than the return to concentrate the current. Electrodes can be placed directly into tumors using either ultrasound, CT, or MR guidance. We prefer the combined use of ultrasonography and CT-fluoroscopy. Currently, most clinicians use either hooked electrodes or internallycooled single or cluster (triple) electrodes with pulsed technique.

\subsubsection{Technique}

As with other ablative therapies, the procedure can be performed either percutaneously, laparoscopically, or at laparotomy. For percutaneous procedures, the $\mathrm{RF}$ is generally applied following local anesthesia with conscious sedation. We prefer to use a benzodiazepam such as medazolam and a narcotic such as fentanyl. An anesthetic cream containing prilocaine and xylocaine can be applied to the skin surface one hour prior to treatment, or subdermal injection of $1-2 \%$ lidocaine can be used for local anesthesia. Continuous cardiovascular and respiratory monitoring is performed.

Radiofrequency electrodes with $2-3 \mathrm{~cm}$ of exposed metallic tip are usually used to deliver the radiofrequency to the tissues. For monopolar treatments, a single electrode is placed within the tumor using ultrasound or CT guidance. Bipolar and multiprobe array systems require the insertion of two or more electrodes. Grounding is achieved by attaching, a large grounding pad to the patient's thigh or back. Proper placement of this pad with a wide area of skin to pad contact is essential for preventing electrical burns at the grounding pad site [76]. The electrode is attached to a $500 \mathrm{kHz} \mathrm{RF}$ generator. $\mathrm{RF}$ is usually applied for $10-30$ minutes. Depending on the technology and generator used, $\mathrm{RF}$ power is either titrated to achieve a specified current or electrode tip temperature. When cooled-tip electrodes are used, a peristaltic pump infuses $0^{\circ} \mathrm{C}$ normal saline into the cooling lumen at a rate sufficient to maintain a tip temperature of $20-25^{\circ} \mathrm{C}[58,59]$.

For a procedure to be considered successful, treatment of all identifiable metastatic disease must be complete (i. e. ablation of all malignant tissue). Ideally, a peripheral margin of at least $0.5-1 \mathrm{~cm}$ of apparently healthy hepatic tissue should be treated with the goal of preventing local recurrence. If adequate margins are not obtained, peripheral tumor growth may occur, and generally will have unfavorable geometry for retreatment. In order to achieve complete treatment, multiple electrode insertions are necessary for most lesions $3-4 \mathrm{~cm}$ in size. Adequate treatment of tumors larger than $4 \mathrm{~cm}$ is unlikely using current technology.

\subsubsection{Clinical Results}

To date, multiple series have been published in which radiofrequency ablation was used for the treatment of hepatic malignancies, and several additional series have been presented at scientific meetings. However, these results must all be viewed as preliminary, and principally an assessment of safety and short-term efficacy, since longterm follow-up has only recently begun to be available. The following section will summarize the results of the published series. 
Rossi et al. treated 50 patients, 39 of which had 41 small HCC nodules and 11 of whom had 13 hepatic metastases [77]. They employed both monopolar and bipolar radiofrequency electrodes, using multiple probe insertions and multiple treatment sessions. All but one of the tumors treated in their series were smaller than $3.5 \mathrm{~cm}$ in diameter. For the 39 patients with HCC, the mean number of treatment sessions was 3.3. Mean follow-up was 22.6 months, and the authors reported a median survival of 44 months. A total of $16(41 \%)$ of 39 patients developed recurrent tumor: $2(5 \%)$ of 39 developed local recurrences; $14(36 \%)$ of 39 developed new lesions. For the 11 patients with metastases, the mean number of treatment sessions was 3.1. Two of these patients underwent surgery within 35 days of RF tumor ablation. Histopathologic examination of the resection specimens showed complete tumor necrosis in $1(50 \%)$ of 2 of these patients. Mean follow-up was 11 months in the remaining 9 patients. In this group, only $1(11 \%)$ of 9 patients was without evidence of metastases at one year following treatment. Of note, however, local recurrence was only seen in $2(22 \%)$ of 11 patients in whom metastases were treated: one who underwent surgery, and one who developed both local recurrence and other liver metastases.

In a subsequent series, Rossi et al. treated 37 patients, 23 of which had $26 \mathrm{HCC}$ nodules, and 14 of whom had a total of 19 hepatic metastases [31]. The mean diameter of the tumor nodules was $2.5 \mathrm{~cm}$. The treatments were performed using hooked needle electrodes, and required an average of 1.4 treatment sessions per lesion. Five patients in their series ultimately underwent surgery 20-60 days following RF tumor ablation. Histopathologic examination of the resected specimens showed recurrent tumor in 1 $(20 \%)$ of these patients (a patient with an HCC larger than $2.5 \mathrm{~cm}$ ). The remaining 21 patients with $\mathrm{HCC}$ and 11 patients with metastases were followed for a mean of 10 or 12 months, respectively. The authors report disease free survival in $15(71 \%)$ of 21 patients with $\mathrm{HCC}$, and $2(18 \%)$ of 11 patients with metastases. Of note, local recurrence was only seen in $3(8 \%)$ of 37 patients: two with $\mathrm{HCC}$ (one who subsequently underwent surgery) and one with metastases.

Solbiati et al. treated 16 patients with 31 metastases from gastrointestinal carcinomas [33]. These tumors measured $1.5-7.5 \mathrm{~cm}$ in diameter; $27(87 \%)$ of 31 were less than 3 $\mathrm{cm}$ in diameter. The treatments were performed using conventional monopolar techniques using both single electrodes and multiple electrode arrays, and required an average of 2.4 treatment sessions per lesion. A complete response (defined as no evidence of local tumor growth by CT and MR imaging six months following treatment) was achieved in $18(58 \%)$ of 31 lesions; all were less than $3 \mathrm{~cm}$ in diameter. Partial tumor necrosis was seen in $13(42 \%)$ of 31 lesions. Necrosis was estimated to be $>80 \%$ of tumor volume in 9 of these lesions ( 6 of which were larger than $3 \mathrm{~cm}$ ) and $<80 \%$ of tumor volume in the remaining four (all of which were larger than $2 \mathrm{~cm}$ ). Disease free survival was achieved in 50\% of patients at a mean follow-up of 16.6 months. Overall survival was $100 \%$ at one year and $61.5 \%$ at two years.

Solbiati et al. subsequently reported a series of 29 patients in whom 44 hepatic metastases from gastrointestinal malignancies (primarily colorectal carcinoma) were treated using internally cooled electrodes [58]. All lesions in this series measured $1.5-4.5 \mathrm{~cm}$ in diameter. Thirty-seven (84\%) of the 44 lesions were treated in a single treatment session; the remaining seven lesions required a second session. The authors report "technical success" (lack of residual unablated tumor at follow-up CT or MR imaging $7-14$ days after the completion of treatment) in 40 (91\%) of 44 tumors. Two patients could not be 
Matching the Energy Source to the Clinical Need / 305

followed beyond 3 months: one underwent surgery 60 days following RF ablation; one was lost to further follow-up after 3 months. Overall, complete tumor necrosis was achieved in $33(75 \%)$ of 44 lesions after a mean follow-up of 7.9 months. In this series, treatment outcome was significantly better in patients with small tumors: local recurrence developed in none of the 12 lesions smaller than $2 \mathrm{~cm}, 14(70 \%)$ of the 20 lesions that were $2-3 \mathrm{~cm}$ in diameter, and $7(58 \%)$ of the 12 lesions larger than $3 \mathrm{~cm}$. Disease free survival was achieved in $16(76 \%)$ of 21 patients at 6 months, $9(50 \%)$ of 18 patients at 12 months, and $3(33 \%)$ of 9 patients at 18 months. Survival at 2 and 3 years is now reported at $67 \%$ and $40 \%$, respectively [78].

Livraghi et al. treated 14 patients with 24 hepatic metastases and one patient with hepatic cholangiocarcinoma using conventional radiofrequency electrodes and simultaneous intraparenchymal saline injection [47]. The metastases measured $1.2-4.5 \mathrm{~cm}$ (mean 3.1 $\mathrm{cm}$ ) in diameter; the cholangiocarcinoma was $2.6 \mathrm{~cm}$ in diameter. Complete necrosis was obtained at 6 months follow-up in $13(52 \%)$ of 25 treated lesions. All of the successfully treated lesions measured smaller than $3.9 \mathrm{~cm}$ in diameter. However, even in the successfully treated lesions, the authors noted that zones of coagulation necrosis were often irregular in shape and unpredictable. This, in combination with the relatively poor results overall, led them to abandon this technique in favor of the use of internally cooled electrodes.

Livraghi et al. subsequently compared radiofrequency ablation and percutaneous ethanol injection for the treatment of small hepatocellular carcinoma [50]. They treated 86 patients with 112 small ( $\leq 3 \mathrm{~cm}$ in diameter) hepatocellular carcinoma with radiofrequency ablation using internally cooled electrodes (42 patients with 52 tumors) or percutaneous ethanol injection (44 patients with 60 tumors). These patients were studied with dual phase spiral computed tomography at least 4 months after treatment. The authors reported complete necrosis in $47(90 \%)$ of 52 tumors treated with radiofrequency ablation and in $48(80 \%)$ of 60 tumors treated with percutaneous ethanol injection. Treatment with radiofrequency ablation required fewer sessions per tumor than did treatment with percutaneous ethanol injection (1.2 versus 4.8$)$. The results of this study suggest that radiofrequency ablation is at least as effective as percutaneous ethanol injection in the treatment of small hepatocellular carcinoma. The authors also noted that the size and shape of RF-induced tumor necrosis generally conformed to the size and shape of the tumor which had been treated, and in many cases was larger than might have been expected on the basis of prior animal and human experience. They postulated the "oven effect," whereby cirrhotic liver surrounding a tumor treated with RF acts as a thermal insulator and facilitates thermally mediated tissue necrosis.

Siperstein et al. treated 6 patients with 13 liver metastases from primary neuroendocrine tumors [37]. The metastases measured $1.5-7.0 \mathrm{~cm}$ in diameter. These authors used a laparoscopic approach with a hooked-electrode needle system. In order to treat these lesions, 1-8 applications of radiofrequency, each lasting 5 - 15 minutes, were needed. The overall procedures lasted between one hour and forty-five minutes and seven hours and five minutes. Follow-up CT scanning suggested a complete ablation of all 13 lesions at 1 week, and $11(100 \%)$ of 11 lesions in four patients followed for 3 months. Longer term follow-up was not reported. The authors also reported symptomatic improvements in these patients with functional tumors. 
Recently, Jiao et al. treated 35 patients with primary and secondary liver tumors who were not considered candidates for curative hepatic resection: 8 with $\mathrm{HCC}$, and 27 with metastases (17 from colorectal carcinoma) [79]. Treatment was performed using internally cooled electrodes either percutaneously under ultrasound guidance (5 patients), or at laparotomy guided by manual palpation and intraoperative ultrasound (30 patients). Intraoperative procedures were performed during Pringle's maneuver in to decrease hepatic perfusion and thereby heat conduction from tissues surrounding RF-treated lesions. Seventeen $(57 \%)$ of 30 patients treated intraoperatively underwent only $R F$ ablation; $13(43 \%)$ of 30 patients underwent combined $R F$ ablation and surgical resection (including 2 patients who initially underwent percutaneous $\mathrm{RF}$ ablation). Overall, 24 $(69 \%)$ of 35 patients were found to have "stable disease" at a mean of 10.1 months of follow-up. Of note, $11(41 \%)$ of 27 patients with hepatic metastases were initially judged to be unresectable, but subsequently underwent resection in combination with RF ablation to tumors in the remaining liver.

Curley et al. have also performed a prospective, nonrandomized RF ablation trial of unresectable malignant hepatic tumors in 123 patients [38]. Tumors were treated percutaneously or during surgery under ultrasound guidance using a hooked array needle system. One hundred and sixty nine tumors (median diameter $3.4 \mathrm{~cm}$, range 0.5 to $12 \mathrm{~cm}$ ) were treated. Forty eight patients $(39 \%)$ had hepatocellular carcinoma, and 75 patients (61\%) had metastatic liver tumors. Percutaneous treatment was performed in 31 patients (35\%) and intraoperative RF in 92 patients $(75 \%)$. There were no treatment-related deaths, and the complication rate was $2.4 \%$. All treated tumors were completely necrotic on imaging studies after completion of RF treatments. With a median follow-up of 15 months, tumor has recurred in 3 of 169 treated lesions $(1.8 \%)$, but metastatic disease developed at other sites in 34 patients $(27.6 \%)$.

Few complications have been reported by these investigators. Rossi et al. reported no complications in their series $[31,77]$. Solbiati et al. observed two cases of self-remitting intra-peritoneal bleeding, one each using conventional and cooled-tip electrodes [33, 58]. One major complication (hemothorax that required drainage) and four minor complications (intraperitoneal bleeding, hemobilia, pleural effusion, cholecystitis) occurred in patients treated with RF ablation were reported by Livraghi et al. [78]. In Curley's series, there were no treatment-related deaths, and the complication rate after $\mathrm{RF}$ ablation was $2.4 \%$ [38].

\subsection{INTERSTITIAL LASER PHOTOCOAGULATION}

Interstitial laser photocoagulation (ILP) is another method for inducing thermally mediated coagulation necrosis which has been employed for percutaneous tumor ablation. For this procedure, flexible thin optic fibers are inserted into the target through percutaneously placed needles, using imaging guidance. The laser provides sufficient energy to allow for significant heat deposition surrounding the fiber tip, inducing protein denaturation and cellular death [23]. As with radiofrequency systems, thermal profiles have been demonstrated to correlate well with the extent of coagulation necrosis observed histopathologically $[30,79]$ as well as with ultrasound $[29,79]$ and T1-weighted MR images $[68,80]$. Clinical studies have been performed predominantly with neodymium: yttrium-aluminum-garnet ( $\mathrm{Nd}: Y A G)$ laser fibers operating at a wavelength of $1,064 \mathrm{~nm}$, which provide relatively good tissue-penetrating power [81]. One to two seconds of high 
power (50-80 watts) laser output results in immediate vaporization of tissues in contact with the laser fiber [82]. With low power ( 1 - 2 watts) over a 500-1,000 seconds, deeper penetration of light and heat are possible, and result in greater volumes of coagulation necrosis [20]. However, even under the best of circumstances, coagulation of no more than $1.6 \mathrm{~cm}$ in diameter can be achieved with a single laser fiber $[30,79]$. For this reason, many investigators have resorted to the use of diffuser tips [83] or beam-splitters with multiple fibers [84], which enable the simultaneous deposition of photoenergy to a larger area of tissue.

\subsubsection{Technique}

As for radiofrequency procedures, laser tumor ablation is most often performed using concious sedation with benzodiazepams and narcotics and local topical lidocaine anesthesia. Ultrasound-guidance is most often used to position biopsy needles (18 - 21 gauge) into the tumor. CT guidance can also be used to position the needle. A plastic guide with multiple evenly spaced holes can be used when multiple needles are to be inserted simultaneously. Laser fibers (thin fiber-optic cable) are then inserted through the cannula of each biopsy needle. The laser fibers are attached to a Nd:YAG laser which is excited at $2-4$ Watts for $5-15$ minutes. A beam splitter is necessary to simultaneously activate multiple laser fibers. Ultrasound is usually used to monitor the ablation in real time, but recent studies have reported results with MR monitoring. As for RF, longerterm imaging follow-up is most often performed with axial imaging (CT and MR).

\subsubsection{Results}

In 1990, Hahl et al. described their experience treating seven patients with malignant liver tumors using a $\mathrm{Nd}: \mathrm{YAG}$ laser at laparotomy [85]. Contact sapphire probes with power settings of $6 \mathrm{~W}$ were placed into the middle of the tumor and temperatures of 41 $45^{\circ} \mathrm{C}$ were maintained $1.5-2.0 \mathrm{~cm}$ from the laser fiber. Percutaneous fine needle biopsies obtained 3 - 5 days post-procedure demonstrated tumor necrosis. However, in $30 \%$ of the lesions, residual viable tumor cells were present. CT imaging obtained four weeks post-treatment also showed signs of necrosis. They reported one fatality in their series, apparently caused by an air embolism.

In 1990, Masters et al. [86] treated four patients with three or fewer hepatic metastases measuring up to $6 \mathrm{~cm}$ in diameter. Primary tumors were of colorectal origin in three cases, and gastric origin in one patient. All procedures were performed under conscious sedation, using a Nd:YAG laser. Up to four 19 gauge needles, each bearing a laser fiber, were inserted percutaneously into the metastases under ultrasound guidance. The fibers were then fired at $1.5-2.0$ watts for 500 seconds. No early or late complications were reported. Ultrasound follow-up at two weeks post-procedure demonstrated that treated metastases became hyperechoic with a circumferential hypoechoic halo. CT follow-up at 2 months demonstrated absence of enhancement of the treated lesion following contrast administration. Three of the treated metastases were unchanged in size, while the fourth continued to increase in size. In 1992, this same group described their experience with the treatment of ten patients with a total of 18 hepatic tumors which were treated using a total of 31 treatment sessions [87]. The treatments were well tolerated and produced radiological evidence of tumor necrosis less than or equal to $3 \mathrm{~cm}$ in diameter. Overall objective response rate, defined as complete treatment of a given lesion, was $44 \%$. 
In 1993, Amin et al. representing the same Middlesex group, described ILP treatment of 55 liver metastases in 21 patients [34]. In many of these patients, multiple fibers (up to 16) were fired simultaneously $(76 \%)$. Greater than $50 \%$ tumor necrosis was achieved in $82 \%$ of the tumors, and $100 \%$ necrosis was achieved in $38 \%$. Metastases smaller than 4 $\mathrm{cm}$ in diameter were treated more effectively, and required fewer treatment sessions than did those larger than $4 \mathrm{~cm}$. Reported complications were minor, including severe pain in four cases, persistent pain for up to 10 days in 11 cases. CT follow-up further identified asymptomatic subcapsular hematomas in four cases and pleural effusions in six cases.

Another report from the same group [88] compared results for the treatment of hepatic metastases using ultrasound-guided percutaneous ethanol instillation (PEI) and ILP. This non-randomized study demonstrated better results with laser therapy than PEI for patients with metastatic disease. Seventy-six liver metastases in 22 patients were treated using either ILP or PEI. Fifty four tumors (median size $2.7 \mathrm{~cm}$ ) were treated with laser, and 22 tumors (median size $1.5 \mathrm{~cm}$ ) were treated with PEI. Follow-up dynamic contrastenhanced CT of the lesions treated with ILP demonstrated well demarcated areas of coagulation necrosis which showed no evidence of contrast enhancement. Coagulation necrosis was greater than $50 \%$ of tumor volume in $87 \%$ of the lesions, while complete necrosis was seen in 52\%. In follow-up CT of the lesions treated with PEI demonstrated patchy areas of non-enhancement in $24 \%$, and no change in $47 \%$. Complete tumor necrosis was not achieved in a single case with PEI, despite the fact that the tumors were small and should have been amenable to such therapy. In addition, pain during treatment was more common and more severe with PEI, than ILP. No major complications were observed using either therapy.

Nolsoe et al. [29] reported the treatment of 16 colorectal metastases in 11 patients using ILP with a tip diffuser. Twelve tumors $(75 \%)$ measuring $1.0-3.7 \mathrm{~cm}$ in diameter (mean $2.4 \mathrm{~cm}$ ) were completely treated. In the remaining four tumors measuring $2-4 \mathrm{~cm}$ in diameter, necrosis was seen throughout most of the lesion, but complete treatment was not achieved. In a later report, this same group reported that the sonographic appearance of treated areas evolved over weeks to months to a pattern consistent with simple hepatic cysts [89].

Vogl et al. recently evaluated MR imaging-guided ILP of liver metastases in 20 patients with 33 metastases from colorectal carcinoma (75\%) or other primary tumors (25\%) [68]. In $69 \%$ of lesions $<2 \mathrm{~cm}$ in diameter, contrast-enhanced MR images demonstrated substantial necrosis immediately post-treatment. Local tumor control was $69 \%$ at 6 months and $44 \%$ at 12 months. Among lesions larger than $2 \mathrm{~cm}$, necrosis was frequently incomplete, with local tumor control of only $41 \%$ at 6 months and $27 \%$ at 12 months.

\subsection{MICROWAVE}

Microwaves are a third thermal energy source which have been used for percutaneous image-guided tumor ablation. In contrast to radiofrequency, where the inserted electrode functions as the active source, in microwave ablation the inserted probes (usually 14 gauge) function as antennae for externally applied energy at $1,000-2,450 \mathrm{mHz}$ [90]. The microwave energy applied to the tissues results in rotation of polar molecules which is opposed by frictional forces. As a result there is conversion of rotational energy into heat [91]. One potential advantage of microwave over RF and laser is that investigational ex- 
vivo studies have shown greater tissue penetration and larger zones of coagulation necrosis with microwave technology. This finding is most pronounced with cooling of the microwave antenna in a fashion similar to cooled-tip RF [92]. In clinical practice, however, arrays of microwave antennas or multiple insertions of a single microwave probe have been necessary to treat lesions greater than $2 \mathrm{~cm}$ in diameter [93-96]. One additional and important limitation of this method is the complexity of microwave antenna design, which limits the antenna to specific lengths corresponding to the microwave generator wave-form. This differs from RF and laser where a more variable length of tissue can be subject to treatment. Even greater limitations in lesion geometry are imposed when microwave arrays are used [97].

\subsubsection{Technique}

Microwave coagulation therapy can be performed both intraoperatively [93 - 96, 98] or percutaneously using conscious sedation [ $99-104]$. Real-time ultrasound imaging has been used in both instances to place a 14 gauge guide needle into the tumor. A single microwave antenna measuring $1.6 \mathrm{~mm}$ in diameter is placed through the guide needle into the tumor. The guide needle is retracted over the shaft of the antenna so as to limit interference during energy deposition. The antenna is connected to a $2,450 \mathrm{mHz}$ microwave generator which provides the necessary energy to induce coagulation. In most studies, 60 Watts are deposited for $60-120$ seconds. Multiple insertions of the antenna with subsequent generator activation are required to treat a given tumor. Intraoperatively, there is no limit to the number of antenna insertions [93 - 96], but no more than three punctures are usually undertaken in any given session, when the therapy is administered percutaneously [99-100]. Multiple treatment sessions are therefore the rule for percutaneous microwave therapy. The efficacy of microwave therapy is measured using tumor markers and diagnostic imaging in a manner analagous to PEI, RF, and laser ablation therapies.

\subsubsection{Results}

Initially, microwave ablation techniques were used by several Japanese investigators for intraoperative applications such as minimizing blood loss during hepatectomy [93 - 98]. Saitsu et al. were the first to report treatment of 21 patients with $\mathrm{HCC}$ less than $5 \mathrm{~cm}$ in diameter using intraoperative microwave coagulation [93]. Recurrence of disease was noted in only 5 patients $(23.8 \%)$ with a single death at 18 months post-procedure. The remaining 20 patients survived to a maximum of 39 months. A larger series of $70 \mathrm{HCC}$ nodules in 46 patients was subsequently treated by this same group [94]. Of these, 42 patients survived a minimum of 4.3 years.

Sato et al. also treated 19 patients with $31 \mathrm{HCC}$ nodules measuring $0.5-9.0 \mathrm{~cm}$ using intraoperative microwave application [96]. In this study multiple probe insertions (mean $=46$, maximum 112 insertions) were used for each tumor with relatively short (30 second) application of high wattage $(70-90 \mathrm{~W})$ output. Using this technique, surgical margins of $1 \mathrm{~cm}$ were achievable in all but 3 lesions. Fourteen patients had all identifiable tumors treated, whereas in five patients other tumor nodules were left untreated with the procedure classified as palliative. In the group with presumed total treatment, no local or distant recurrence was observed over one year. In these patients, elevated AFP levels returned to normal after treatment tumors were observed to decrease in size on serial follow-up CT scans. Ten of these patients were disease free at $14-64$ 
months of follow-up (mean 24 months). Of the remaining four patients whose tumors were felt to be totally treated, two developed new foci of $\mathrm{HCC}$, one developed a local recurrence (presumed treatment failure) and one died.

Hamazoe et al. treated $21 \mathrm{HCC}$ nodules (to $6.5 \mathrm{~cm}$ maximal dimension) in eight patients using 222 insertions of the microwave antenna [98]. CT imaging findings and needle biopsy at one month post-treatment showed no evidence for tumor recurrence. No deaths were reported over a mean 16 months of follow-up, but new tumor nodules were seen in three of the eight patients.

Percutaneously microwave coagulation therapy (PMCT) performed with imagingguidance rather than at laparotomy has also recently been reported [ $99-104]$. These studies, although preliminary, suggest that microwave ablation therapy will certainly have a significant role in the future.

Seki et al. initially reported the treatment of 18 patients with solitary, surgically unresectable $\mathrm{HCC}$ nodules measuring less than $2 \mathrm{~cm}$ in greatest dimension [99]. Microwave energy was applied at $60 \mathrm{~W}$ for 120 seconds to the tumor and a surrounding margin of apparently normal hepatic tissue. One to four probe insertions at separate treatment sessions were required to achieve adequate necrosis. No serious side effects or complications were encountered. Over a follow-up period of 11-33 months, no local recurrence was detected, AFP levels were reduced in all patients, and imaging findings (similar to those reported for RF ablation) suggested complete local treatment. One patient died at 22 months, while the remaining 17 patients were alive at the end of the study. A second report described PMCT performed for small solitary intrahepatic colorectal metastases measuring $\leq 3.0 \mathrm{~cm}$ in diameter. In 15 patients, a $25 \mathrm{~cm}$ long and $2.0 \mathrm{~mm}$ thick microwave antenna electrode was inserted percutaneously into the tumor area under ultrasonic guidance. Thirteen of the 15 metastatic tumors were completely ablated with 3-10 applications of microwave irradiation at 80 watts. Over the $9-37$ month follow-up period, 10 patients survived. No local recurrence was detected when adequate tumor coagulation was initially achieved, and no serious side effects or complications were encountered during or after the PMCT. Metastatic diseases distant from the treatment site was responsible for four of five patient deaths in this study [101].

Recently this group has also compared the efficacy of PMCT and percutaneous ethanol injection therapy (PEI) in the treatment of patients solitary hepatocellular carcinomas measuring $\leq 2 \mathrm{~cm}$ in greatest dimension, and suggested that PMCT may be superior to PEIT for the local control of moderately or poorly differentiated small HCC [106]. In this retrospective, nonrandomized study, 90 patients were treated with PMCT or PEI. Of the 43 patients with well-differentiated HCC, 23 were treated with PMCT and 20 with PEI. Of the 47 patients with moderately or poorly differentiated HCC, 25 were treated with PMCT and 22 with PEI. Overall 5-year survival for patients with well-differentiated HCC treated with PMCT $(70 \%)$ and PEI (78\%) were not significantly different and no difference between the patterns of recurrence were observed. However, among the patients with moderately or poorly differentiated $\mathrm{HCC}$, overall 5-year survival with PMCT was significantly better than with PEIT $(78 \%$ vs. $35 \%, p=0.03)$. Additionally, for patients with moderately or poorly differentiated $\mathrm{HCC}$, local recurrence was observed in 9 of $22(41 \%)$ treated with PEI, whereas only 2 of 25 patients $(8 \%)$ treated with PMCT had a local tumor recurrence. 
Murakami et al. have also used a similar percutaneous microwave coagulation technique to treat nine hepatocellular carcinomas exceeding $3 \mathrm{~cm}$ in diameter in nine patients [100]. All patients had failed transcatheter arterial embolization therapy within 2 weeks prior to microwave ablation therapy. A single 14 gauge needle electrode was positioned precisely within the lesion under sonographic guidance. Microwaves of $2,450 \mathrm{MHz}$ were applied for 60 seconds at 60 watts. Three to 12 repositionings of the electrode were required for any given tumor. All patients tolerated the treatments well, with no serious complications observed. Dynamic CT revealed non-enhancing areas indicative of coagulation necrosis enveloping the tumor in every case. Follow-up CT at one month demonstrated a slight reduction in the size of this hypodense region, usually to an area smaller than the original diameter of the treated tumor. Imaging follow-up at 4-9 months showed that five lesions were completely treated without signs of local recurrence.

Matsutaka et al. have reported the results of their 3-year experience using US-guided PMCT [103]. A total of 27 inoperable liver tumors in 24 patients were treated and were followed for 4 - 40 months (18 month average). Twenty tumors were hepatocellular carcinomas (HCCs) and 7 were metastases. Overall survival was $83 \%$ at 1 year and $69 \%$ at 2 years. Adequate treatment was obtained in $70 \%$ of tumors measuring less than $3 \mathrm{~cm}$, while complete treatment was achieved in only $55 \%$ of tumors larger than $30 \mathrm{~mm}(\mathrm{p}<$ 0.05 ). Tumor became smaller or disappeared in $85 \%$ of the well differentiated HCCs, and in only $25 \%$ of the moderately differentiated HCCs. None of the poorly differentiated HCCs responded. In metastatic tumors, complete local therapy was achieved with PMCT in $57 \%$ of cases. Slight pain (24\%), fever $(20 \%)$ and subcutaneous hematoma $(8 \%)$ were noted immediately following the procedure. In two cases of poorly differentiated HCC, needle tract seeding was observed.

The complication rate for PMCT has recently been reported by Shimada et al. [104]. In this series, complications were noted following PMCT treatment in $14.2 \%$ of 42 patients with hepatocellular carcinoma and $20.6 \%$ of the 29 with metastatic liver. The complications included abscess, biloma, bleeding, hepatic failure, and dissemination of cancer cells. Increased tumor size $(>4 \mathrm{~cm}$ ) and tumor location (high in the dome of the liver) were associated with a higher complication rate.

\subsection{CRYOTHERAPY}

Cryotherapy is a method of tumor ablation which uses cooled probes to freeze and destroy areas of tissue measuring up to $8 \mathrm{~cm}$ in diameter [105]. The procedure is currently predominantly performed intraoperatively, as probes measuring $3 \mathrm{~mm}$ in diameter or larger are necessary to deliver optimal quantities of liquid nitrogen to the probe tip. Although cryotherapy is technically not a percutaneous procedure, this method will be discussed in this chapter as probes suitable for percutaneous use are currently under development [65]. Published results of hepatic cryotherapy are now available for almost 900 patients. Its safety is well established and its clinical role in treating patients with unresectable hepatoma or liver metastases from colorectal carcinoma is well supported by tumor marker and survival data. Additionally, the results in the treatment of neuroendocrine liver metastases are promising. However, as for other methods of minimally-invasive therapy, the proportion of patients who might be usefully treated with this technique is not yet well established. 
Destruction of tumor tissue by cryotherapy is attributed to several mechanisms. Rivoire et al. [106] have shown that the temperature threshold required to obtain complete necrosis in normal liver was $-15^{\circ} \mathrm{C}$. Cooper et al. [107] have further defined the cytotoxic mechanisms of cryotherapy. Internal freezing results in membrane rupture during subsequent thawing as a result of ice crystals. This leads to solute-solvent shifts, which exposes cells to hyperconcentrated electrolytes. Cellular dehydration ensues. Experimental studies of cryosurgery in normal and tumorous rat liver [108] suggest that microcirculatory shutdown after cryosurgery may also be a contributing factor to tumor necrosis by ischemic mechanisms. Thus, tissue destruction with cryoablation is fundamentally different from that of cooled-tip RF where the cooling of tissues to $15-25^{\circ}$ $\mathrm{C}$ only facilitates deposition of greater RF energy and does not contribute to induction of coagulation necrosis.

\subsubsection{Technique}

Intra-operative ultrasound is performed in order to identify hepatic lesions and to monitor the freezing process to ensure that the cryolesion includes the tumor mass [105]. Cryoprobes measuring 3-10 $\mathrm{mm}$ are usually used. Larger probes tend to produce larger areas of tissue destruction $(6-8 \mathrm{~cm})$, whereas smaller $3 \mathrm{~mm}$ probes produce approximately $3-3.5 \mathrm{~cm}$ of tissue destruction. Liquid nitrogen $\left(-196^{\circ} \mathrm{C}\right)$ is introduced into the probe in a controlled fashion, resulting in freezing of the surrounding tissues. Ultrasonography has been used to monitor the area treated in real-time as the margin of frozen tissue appears hyperechoic when compared to both normal liver and tumor. The duration of freezing ranges from 5 to 20 minutes, with larger lesions requiring extended freezing times. The area to be frozen (i.e. the "cryoball") must extend at least $0.5-1.0 \mathrm{~cm}$ beyond the tumor margin to ensure adequate treatment of the lesion.

Ten to 20 minutes of thawing are allowed before additional cryotreatments are performed. Frozen tissues appear hypoechoic after thawing compared with normal unfrozen liver. Usually at least two freeze-thaw cycles are performed. Ravikumar et al. [109] demonstrated that two or three freeze-thaw cycles are $100 \%$ effective in controlling established rat colon tumor isografts and preventing isograft take, while one freeze-thaw cycle leads to suboptimal results. Stewart et al. [110] have further demonstrated clinically that significantly higher peak serum AST levels are seen when a double-freeze cycle is used, as compared to a single period of tissue freezing. Elevated AST presumably corresponds to increased tissue damage.

\subsubsection{Intraprocedural Monitoring}

Real-time monitoring of the procedure using ultrasound has been previously described. Ex-vivo studies by Lam et al. have demonstrated that the hyperechoic rim seen during freezing is caused by reflection of ultrasound waves at the interface between unfrozen and frozen liver as a consequence of an increased acoustic impedance of frozen liver [111]. This increased acoustic impedance is due to the decrease in elasticity of hepatic tissue as it freezes. Posterior acoustic shadowing is partly due to the attenuation of the incident ultrasound waves by reflection at the interface between unfrozen and frozen liver, and is also dependent on the crystalloid-protein content of hepatic parenchyma. Correlation in size between the ultrasonographic cryolesion and the measured hepatic ice ball is excellent for cryolesions less than $50 \mathrm{~mm}$ in diameter [106]. 
Studies in animals have demonstrated that $\mathrm{CT}$ and MR can also be used for intraprocedural monitoring. Reiser [112] has shown that in pigs, CT is useful for continuousmonitoring of ice ball formation, and can do so with high spatial resolution. Near realtime MR imaging of cryoablation has also been performed in normal rabbits. Matsumoto et al. [113] have demonstrated that $M R$ images obtained during the freezing procedure can accurately depict the area of final necrosis. Histologic changes at each stage of lesion development correlated well with MR signal intensities on follow-up images. However, most of the currently available cryotherapy systems are incompatable with the strong magnetic fields of the MR environment. To date, all clinical studies have used intraoperative ultrasound for imaging guidance.

\subsubsection{Follow-up Imaging}

CT has been the primary imaging modality used in clinical follow-up. McLoughlin et al. [114] and Kuszyk et al. [115] performed CT in patients who underwent hepatic cryoablation. Cryolesions appeared primarily as areas of hypodensity, often with extension to the liver capsule. In Kuszyk's study, approximately one third of the 28 treated tumors contained air, and over $90 \%$ contained hemorrhage. Peripheral enhancement was demonstrated in approximately half of the lesions evaluated with intravenous contrast material. In this study, cryolesions were wedge shaped (54\%), round $(29 \%)$, or teardrop shaped $(21 \%)$. Other associated findings included subcapsular hemorrhage (29\%), perihepatic fluid collections $(43 \%)$, right-sided pleural effusion $(93 \%)$, left-sided pleural effusion (64\%), atelectasis $(93 \%)$, and ascites $(7 \%)$. One iatrogenic portosystemic shunt was detected. The authors therefore concluded that the postoperative CT appearance of hepatic lesions treated with cryoablation in patients without complications mimics that seen in the liver of patients with hepatic abscesses or infarct. Careful analysis of all studies was advocated to avoid confusing normal findings related to the procedure with those related to procedural complications. CT is therefore usually performed early in the post-procedural period to serve as a baseline for detecting superimposed complications.

\subsubsection{Tumor Markers}

Depending on tumor type treated (colorectal metastases or HCC), CEA and AFP levels are also monitored at regular intervals, often every three months. Preketes et al. [116] have demonstrated that CEA reduction after cryotherapy for liver metastases from colon cancer predicts survival, with a 50\% increase in the maximum percentage fall in the CEA level associated with one-tenth the risk of death. In this study an increase in the maximum percentage fall in CEA of $50 \%$ from 25 to $75 \%$ was associated with an increase in the median survival from 240 days to over 2 years.

\subsubsection{Results}

Zhou et al. [117 - 118] reported the use of cryosurgery for the treatment of 60 patients with primary liver cancer, beginning in 1973. The procedures were performed at laparotomy, and epidural anesthesia was used in most cases. Cryosurgery was performed with a hollow, plate-like probe measuring $3-5 \mathrm{~cm}$ in diameter which was placed in direct contact with the tumor. Each tumor was subject to 15-20 minutes of freezing. Intraoperative ultrasound monitored the progress of ablation. The postoperative course 
was uneventful in all patients, and there was no peri-operative mortality. In addition, no post-operative complications such as rupture of tumor, secondary bleeding, bile leakage, or abdominal infection were encountered. Survival at $1,2,3,4$, and 5-years was $52 \%$, $34 \%, 21 \%, 16 \%$, and $11 \%$, respectively. Among the 21 patients with tumor nodules less than or equal to $5 \mathrm{~cm}$ in diameter, survival was increased to $76 \%, 62 \%, 50.0 \%, 41 \%$, and $38 \%$, respectively. In 1993 Zhou et al. [119] reported a larger series of 113 patients with hepatic cancer, including 107 patients with primary liver cancer and 6 patients with hepatic metastases, who were treated with cryotherapy using similar technique. Again, no operative mortality or complications were seen. The 5-year and 10-year survival was $22 \%$ and $8 \%$, respectively, for the 107 with $\mathrm{HCC}$ and $49 \%$ and $17 \%$, respectively, for the 32 patients with small $(<5 \mathrm{~cm})$ tumors. Of the six treated metastases, survival ranged from 2-90 months (mean, 23.2 months).

In 1991, Ravikumar et al. [120] reported their 5-year experience with cryosurgery for insitu ablation of liver tumors. Livers were exposed at laparotomy, and tumors were subjected to two freeze-thaw cycles using liquid nitrogen delivered via insulated probes. Cryoablation was monitored using intraoperative ultrasonography. Of the 32 patients in their study, 24 had colorectal metastases, three had hepatomas; two had neuroendocrine tumors; and three patients had other forms of malignancy. Tumor response during longterm follow-up was evaluated with tumor markers and CT. Median follow-up was 24 months, ranging from 5 to 60 months. Disease free survival was seen in $28 \%$, while $34 \%$ were alive with disease; and $38 \%$ died. Treatment failure included both liver and extrahepatic disease in $54 \%$, liver disease only in $32 \%$, and extrahepatic disease only in $14 \%$.

Preketes [121] treated 94 patients with cryotherapy. Forty two patients with nonresectable hepatic metastases of colorectal origin underwent cryotherapy combined with 5-FU and folinic acid chemotherapy via an indwelling hepatic artery port. Mean followup was 432 days, and life-table analysis showed a median survival of 627 days. Eighty percent of patients with initially elevated CEA levels demonstrated a reduction posttreatment, and $23 \%$ achieved a return to normal CEA levels for a mean duration of 350 days. Regional chemoperfusion for 3 months following cryotherapy was strongly associated with improved survival.

Cuschieri et al. [122] have developed a multineedle cryotherapy system which permits the simultaneous use of three insulated cryoneedle probes. Eighteen patients with secondary and 4 patients with primary liver cancer were treated using this system. Intraoperative bleeding was encountered in three patients undergoing high-volume hepatic freezing, but was easily controlled. A slight fall in core body temperature, averaging $0.4^{\circ} \mathrm{C}$, was encountered in $46 \%$ of patients. One post-operative death from liver failure was observed. A right-sided pleural effusion developed in two patients after freezing of lesions on the superior surface of the right lobe. Forty one percent developed recurrence at the frozen site or elsewhere in the liver within 12 months of follow-up, and were thus felt to have derived no clinical benefit from the cryotherapy.

Weaver [123] treated 47 patients with documented colorectal metastases limited to the liver with cryosurgery and/or surgical resection. Each lesion was frozen to $196^{\circ} \mathrm{C}$ for 15 minutes, thawed for 10 minutes, and frozen again for 15 minutes using intraoperative ultrasound guidance. Follow-up was performed for 24 to 57 months (median 26 months) with CT imaging every six months, and serum CEA levels monthly. Survival at 24 
Matching the Energy Source to the Clinical Need / 315

months was $62 \%$, with $11 \%$ of patients disease free at a median follow-up of 30 months. Reported complications included myoglobinuria, coagulopathy, pleural effusions, and bile duct injuries, with two deaths $(4 \%)$ occurring because of multisystem organ failure with irreversible coagulopathy.

Onik et al. [124] have treated 57 patients with unresectable hepatic metastases using cryosurgery. One to 16 lesions (mean 4.6) were treated in each patient, $73 \%$ of which had bilobar disease. Although 25 patients $(42 \%)$ were treated with combined surgical resection and cryotherapy, disease-free survival was only $27 \%$ at a mean follow-up of 21 months.

Kirgan et al. [125] treated 67 patients with liver metastases using cryosurgical ablation. Thirty seven percent were treated by cryoablation alone, and $63 \%$ underwent cryoablation plus resection and/or infusion chemotherapy. Morbidity was $19 \%$, and two patients required re-operation for either bleeding or wound dehiscence. Other complications included: thrombocytopenia requiring transfusion (4), pleural effusion requiring thoracentesis (2), renal failure requiring dialysis, ascites, GI / biliary fistula (2), and pneumonia. Mortality was $1 \%$. The mean postoperative CEA decrease was $56 \%$ in the $74 \%$ of patients with colorectal metastases whose CEA levels were elevated preoperatively.

Shafir [126] treated 39 patients with liver tumors using a liquid nitrogen cryoprobe at minus $196^{\circ} \mathrm{C}$. These patients also received postoperative chemotherapy. Twenty five patients had colorectal metastases, 3 had gastric tumors, 4 had HCC, 6 had carcinoid tumors, and one had a gastrinoma. Postoperative transient elevation of liver function tests and thrombocytopenia were noted in all cases. No operative mortality was encountered. All patients whose cryoablation was judged to be complete were alive at a mean follow-up of 14 months. Thirteen patients (33\%) had evidence of recurrent disease and $20(51 \%)$ were free of disease. Five patients whose treatment could not be completed died 3 - 9 months postoperatively.

Korpan has also stratified and treated 123 patients with liver metastases in a long-term prospective, randomized clinical trial using cryotherapy $(n=63)$ and conventional surgical techniques $(n=60)$ [127]. A majority of tumors were of colorectal origin $(65 \%$ vs. $68 \%$ ). Hepatic cryoablation was performed by means of probes of different roughly disk design from phi $5 \mathrm{~mm}$ to $55 \mathrm{~mm}$ which permitted the creation of a frozen tissue volume of $40 \mathrm{~cm}^{3}$ to $180 \mathrm{~cm}^{3}$ over 7 to 32 minutes. A 3-year survival rate of $60 \%$ was achieved for cryotherapy vs. $51 \%$ for conventional surgery. 5-year survival was $44 \%$ with cryotherapy and $36 \%$ with surgey. Twelve patients (19\%) treated with cryotherapy, versus 5 patients $(8 \%)$ treated with surgery, survived 10 years. The disease-free survival was $30 \%$ with cryotherapy and $18 \%$ with surgery with intrahepatic tumor recurrence in 54 patients $(85 \%)$ and in 57 patients (95\%), respectively. Tuse, this 10-year prospective, randomized clinical trial suggests that hepatic cryosurgery is effective in the treatment of resectable and nonresectable liver metastases with extended survival in these patients.

\subsection{HIGH-INTENSITY FOCUSED ULTRASOUND}

High-intensity focused ultrasound (HIFU) is a transcutaneous technique which has also recently been studied as potential method for the minimally invasive treatment of 
localized malignancy [128]. This technique uses a parabolic transducer to focus the ultrasound energy at a distance which creates a focused beam of energy with very high peak intensity. This focusing of energy has been likened to using a magnifying glass to focus sunlight [129]. The focused energy is transmitted transcutaneously into the targeted tissue without requiring percutaneous insertion of an electrode or transducer. The ultrasound energy absorbed by tissue is converted to heat, which ablates tissue via coagulation necrosis. Using a $4 \mathrm{MHz}$ transducer and a power intensity $550 \mathrm{~W} / \mathrm{cm}^{2}$ for five seconds, temperature in excess of $80^{\circ} \mathrm{C}$ can be produced in rat liver [130]. Areas of coagulation necrosis have been shown at histopathology to have a spatially sharp demarcation between regions of normal and necrotic tissue. By using by a suitable acoustic frequency regions of tissue destruction can be induced at depths of up to at least $10 \mathrm{~cm}$ with exposure times of the order of 1 second [131]. One main potential benefit of HIFU is that the focused ablative energy can destroy a selected target without causing damage to the intervening tissues. Furthermore, since insertion of a percutaneous probe is not required, HIFU can be considered the least invasive of the "minimally invasive" therapies.

\subsubsection{Technique}

Ultrasound and MR have been used to target the focus of tissue to be treated [128 - 137]. Once this region has been selected, the focused transducer is coupled to the skin with acoustic coupling gel. Power levels and frequency are selected based upon the depth of the lesion to be treated and the absorption characteristics of intervening tissues. A computer is often used to assist in these complex calculations. Current technology can only produce millimeter sized volumes of coagulated tissue for each HIFU application (15 seconds). Multiple applications of HIFU are therefore necessary to completely treat lesions of large enough size to be detectable at diagnostic imaging. MR and computer tracking are often used in an attempt to insure that contiguous coagulation necrosis is achieved within the tumor, without leaving intervening areas of untreated tumor [132].

\subsubsection{Results}

Several investigators have studied the effects of HIFU for the treatment of liver tumors in animal models. At this time, however, results from clinical trials have as of yet been published. Moore et al. [133] first used a Morris hepatoma model in the rat for this purpose. Animals were divided into four groups of ten each: 1) untreated controls; 2) single dose intraperitoneal cyclophosphamide; 3) HIFU only; and 4) both chemotherapy and HIFU. HIFU was administered with a $5.5 \mathrm{~cm}$ diameter $4 \mathrm{MHz}$ quartz transducer at $400 \mathrm{~W} / \mathrm{cm} 2$ focal intensity. The entire tumor was insonated in $1 \mathrm{~mm}$ increments using a 4 second on/11 second off treatment cycle. Tumor volume at four weeks in all treated animals was significantly smaller than in controls, with tumor volume for animals treated with both HIFU and chemotherapy significantly smaller than for those treated with either therapy alone, suggesting a synergistic effect of chemotherapy and HIFU. Yang et al. [134] used a similar Morris rat hepatoma model in which HIFU was administered with a lens-focused $4-\mathrm{MHz}$ transducer at $550 \mathrm{~W} / \mathrm{cm}^{2}$ peak intensity. Significant inhibition of tumor growth (65\%-93\%) was seen in the 56 rats treated with HIFU at 3-28 days posttreatment.

Yang et al. [135] further used a transcutaneously focused HIFU system to coagulate normal liver tissue in rabbits using a subcostal approach. A computer controlled the 
HIFU exposure time and transducer movement in order to destroy a preselected tissue volume. Simultaneous sonography monitored the tissue response. In nine of ten rabbits, a sharply demarcated area of coagulation necrosis was produced. No damage was found in the intervening tissues in the six animals with adequate acoustic coupling and proper beam path applied. Poor acoustic coupling and poor targeting did however result in unintended coagulation of intervening tissues of 4 animals. Sibille et al. [136] analyzed treatment for HIFU in normal and VX2 carcinoma-bearing rabbit liver in 74 rabbits. A 1 $\mathrm{MHz}$ transducer with a $7.5 \mathrm{~kW}$ power amplifier was used. HIFU energy intensity ranging from 1,470 to $5,500 \mathrm{~W} / \mathrm{cm}^{2}$ and exposure times from $0.5-5$ seconds were studied at a constant depths within the liver. In normal rabbits, the volume of coagulation necrosis increased with exposure time at constant intensity, with a negative correlation between intensity and exposure time. When the output power was adjusted as a function of the path length, lesion size was nearly constant. In VX2 rabbits, tumor destruction rates were significantly higher in rabbits treated at $500 \mathrm{~W} / \mathrm{cm}^{2}$ than in rabbits treated at 1,365 $\mathrm{W} / \mathrm{cm}^{2}$. At intensities of $3,000 \mathrm{~W} / \mathrm{cm}^{2}$, perforation of neighboring organs was seen in 7 of 11 rabbits. Prat et al. [137] further studied HIFU using rabbits bearing a solitary VX2 liver tumor. Either one or two consecutive HIFU procedures were used. No mortality was observed. After one HIFU procedure $76 \pm 16 \%$ of the initial tumor volume was destroyed; and $94 \pm 6 \%$ of the tumor was destroyed following two HIFU procedures. Following treatments, the treated tumor was re-injected into the thigh of a second animal. Untreated hepatic tumors induced tumors at 3 weeks in thighs of all recipient rabbits, but tumors treated with one HIFU procedure induced tumors in only $31 \%$ of cases. Tumors treated with two HIFU procedures did not induce tumor growth in any recipient.

\subsubsection{Limitations}

Limitations of HIFU for the treatment of liver neoplasms include the requirement of a suitably wide acoustic window, as a bone or air interface will limit ultrasound penetration. Another key limitation to the implementation of HIFU lies in the fact that only tiny volumes of tissue can be coagulated with each HIFU application. MR tracking with sequential overlap of the small volumes of coagulation may help to overcome this problem, however, the long duration of such procedures (lasting upwards of an hour for a $2 \mathrm{cc}$ volume) and issues such as patient and organ motion virtually ensure that uniform contiguous coagulation will not occur. This is especially relevant to the treatment of liver lesions, where respiratory motion presents a significant challenge. Larger focal spots capable of destroying larger volumes of tissue must therefore be developed before this modality can come into the forefront of tumor therapy.

Recently, Deardorff and Diederich have reported the development of a percutaneously inserted ultrasound applicator for thermal ablation therapy $[43,138]$. The performance characteristics and thermal coagulation of tissue produced by directional air-cooled, direct-coupled interstitial ultrasound applicators were evaluated. Prototype applicators (of $2.2 \mathrm{~mm}$ diameter) were constructed using cylindrical transducers sectored into angular active zones of 90 degrees, 200 degrees, 270 degrees, and 360 degrees. Thermal performance of the applicators was characterized through high temperature heating invivo (porcine thigh muscle, 11 trials) and in-vitro (bovine liver, 46 trials). Results demonstrated directional coagulation of tissue, with good correlation between the angular extent of the lesions and the active acoustic sector. Radial depth of coagulation with a 200 degrees applicator extended $8-17 \mathrm{~mm}$, with a heating time of $1-10$ minutes. Thus, although this device is more invasive than excorporal HIFU, it has the potential to 
overcome several of its limitations including lesion targeting, tissue penetration, and volume of coagulation.

\section{FUTURE TRENDS FOR THERMAL ABLATION THERAPY}

The ultimate goal of tumor therapy is complete eradication of all malignant cells. Given the high likelihood of incomplete treatment by heat based modalities alone, the case for combining thermal ablation with other therapies such as chemotherapy or chemoembolization cannot be overstated. A similar, multidisciplinary approach including surgical, radiation, and chemotherapy is used for the treatment of most solid cancers. The belief that we can reliably destroy all tumors using only one technique is likely overly optimistic, given the variety of tumor types and organ sites. Combination therapy is a key avenue of current ablation research.

Presently, many thermal ablation devices are being studied with multiple commercial devices now becoming available. Given the rapid pace of evolution in the state of the art for ablation technologies, it is too early to confidently predict which method (if any) will prove dominant for any given clinical application. Competitive technologies must be able to ablate the desired volume of tissue in a reproducible and predictable fashion. However, it is more than likely that other factors, including ease of clinical use and cost, will play a role in determining which of these technologies will receive the greatest attention.

\section{CONCLUSIONS}

Percutaneous, image-guided thermal ablation therapy is an exciting and emerging arena that has thus far provided optimistic preliminary results for the minimally-invasive treatment of selected focal hepatic neoplasms. These minimally invasive techniques offer several distinct advantages over the conventional surgical approach to the treatment of small hepatic malignancies, in that they are 1) less invasive, 2) less expensive, and 3) can be performed on an outpatient basis using conscious sedation. Multiple studies have demonstrated that these treatments can cause destruction of tumor with low morbidity and mortality, though best results have been seen with lesions smaller than $3 \mathrm{~cm}$. However, further experience, with larger cohorts of patients followed for longer periods of time are required in order to better understand the efficacy and appropriate role for these therapies.

Key questions that still need to be addressed include: definition optimal methods and techniques for heating tumors; identification of optimal diagnostic imaging strategies to guide therapy and clinical follow-up; and determination of clinical impact. For tumor heating, one must consider both which technical innovations will enable efficient and efficacious energy deposition, and which biologic factors can be successfully modulated to increase heat deposition and retention within the treated tumor. The answers to these questions will require substantial further research, which is ongoing at multiple tertiary centers. It is hoped that this work, and well conducted randomized, multi-center trials will determine the proper role for this promising, new paradigm of thermal ablation and the role for these technologies. Given the pace of recent technologic development for 
many of the methods discussed, further technologic advances allowing for easier and more efficacious treatment of hepatic malignancies are anticipated in the near future.

\section{REFERENCES}

1. Goldberg SN, Livraghi T, Solbiati L, Gazelle GS. In situ ablation of focal hepatic neoplasms. In: GS Gazelle, S Saini, and PR Mueller, eds. Hepatobiliary and pancreatic radiology: Imaging and Intervention. New York. Thiema Medical Pub. 1997: 470-502

2. De Sanctis JT, Goldberg SN, Mueller PR. Percutaneous treatment of hepatic neoplasms: A review of current techniques. Cardiovasc Intervent Radiol 1998; 21:273-296

3. Livraghi T, Giorgio A, Marin G, et al. Hepatocellular carcinoma and cirrhosis in 746 patients: long-term results of percutaneous ethanol injection. Radiology 1995; 197:101-108

4. Shiina $S$, Tagawa $K$, Niwa $Y$, et al. Percutaneous ethanol injection therapy for hepatocellular carcinoma: results in 146 patients. AJR 1993; 160: 1023-1028.

5. Ballantyne GH and Quin J. Surgical treatment of liver metastases in patients with colorectal cancer. Cancer 1993; 71: 4252-66

6. Hughes KS, Simon R, Songhorabodi S, et al. Resection of the liver for colorectal carcinoma metastases: a multi-institutional study of indications for resection. Surgery 1988; 103: 278-88

7. Garre C. Contribution to surgery of the liver. Bruns Beitr Klin Chir 1888; 4: 181.

8. Fegiz G, Ramacciato G, D'Angelo F, et al. Patient selection and factors affecting results following resection for hepatic metastases from colorectal carcinoma. Int Surg 1991; 76: 58-63

9. Steele G, Bleday R, Mayer RJ, et al. A prospective evaluation of hepatic resection for colorectal carcinoma metastases to the liver: gastrointestinal tumor study group protocol 6584. J Clin Oncol 1991; 9: 1105-12

10. Gayowski TJ, Iwatsuki S, Madariaga JR, et al. Experience in heaptic resection for metastatic colorectal cancer: analysis of clinical and pathologic risk factors. Surgery 1994; 116: 703-710

11. Nakamura S, Yokoi Y, Suzuki S, et al. Results of extensive surgery for liver metastases in colorectal carcinoma. Br J Surg 1992; 79: 35-38

12. Saenz NC, Cady B, McDermott WV, et al. Experience with colorectal carcinoma metastatic to the liver. Surg Clin North Am 1989; 69: 361-70

13. Cady B and Stone MD. The role of surgical resection of liver metastases in colorectal carcinoma. Sem Oncol 1991; 18: 399-406

14. Ridge JA and Daly JM. Collective review: treatment of colorectal hepatic metastases. Surg Gynecol Obstet 1985; 161: 597-607

15. Seegenschmiedt MH; Brady LW; Sauer R. Interstitial thermoradiotherapy: review on technical and clinical aspects. Am J Clin Oncol 1990;13: 352-63

16. Overgaard J. Hyperthermia as an adjuvant to radiotherapy. Review of the randomized multicenter studies of the European Society for Hyperthermic Oncology. Strahlenther Onkol 1987; 163:453-457

17. Larson TR, Bostwick DG, Corica A. Temperature-correlated histopathologic changes following microwave thermoablation of obstructive tissue in patients with benign prostatic hyperplasia. Urology 1996; 47:463-469 
18. Goldberg SN, Gazelle GS, Halpern EF, Rittman WJ, Mueller PR, Rosenthal DI. Radiofrequency tissue ablation: Importance of local temperature along the electrode tip exposure in determining lesion shape and size. Acad Radiol, 1996; 3:212-218

19. Goldberg SN, Tanabe KK, Solbiati L, Gazelle GS, Hahn PF, and Mueller PR. Treatment of intrahepatic malignancy with radiofrequency ablation: Radiologicpathologic correlation in 16 patients. AJR 1997; 168:121 (abstr).

20. Thomsen S. Pathologic analysis of photothermal and photomechanical effects of laser-tissue interactions. Photochem Photobiol 1991; 53:825-35

21. Cosman ER, Nashold BS, Ovelman-Levitt J. Theoretical aspects of radiofrequency lesions in the dorsal root entry zone. Neurosurg 1984, 15:945-950

22. Trembley BS, Ryan TP, Strohbehn JW. Interstitial Hyperthermia: physics, biology and clinical aspects. In: Urano M, Douple E (eds.), Phy sics of Microwave Hyperthermia. In Hyperthermia and Oncology. Vol 3, VSP, Utrecht, the Netherlands, 1992, pp. 11-98

23. Brown SG. Laser-tissue interactions, in Krausner N (ed): Lasers in Gastroenterology. London, Chapman and Hall Medical, 1991, pp. 37-50

24. Amin Z, Brown SG, Lees WR. Liver tumor ablation by intersitial laser photocoagulation: review of experimental and clincial studies. Semin Int Rad 1993; 10:88-100

25. Cline HE, Hynynen $\mathrm{K}$., Watkins RD, et al. Focused US system for MR imagingguided tumor ablation. Radiology 1995; 194:3:731-737

26. Honda N, Guo Q, Uchida H, Ohishi H, Hiasa Y. Percutaneous hot saline injection therapy for hepatic tumors: an alternative to percutaneous ethanol injection therapy. Radiology 1994; 190:53-57

27. McGahan JP, Brock JN, Tessluk H, Wei-Zhong G, Schneider P, Browning PD. Hepatic ablation with use of RF electrocautery in the animal model. JVIR 1992; 3:291-297

28. Goldberg SN, Gazelle GS, Dawson SL, Rittman WJ, Mueller PR, Rosenthal DI. Tissue ablation with radiofrequency: effect of probe size, gauge, duration, and temperature on lesion volume. Acad Radiol, 1995; 2:399-404

29. Nolsoe CP, Torp-Pedersen S, Burcharth, et al. Interstitial hyperthermia of colorectal liver metastases with a US-guided ND-YAG laser with a diffuser tip: A pilot clinical study. Radiology 1993; 187:333-337

30. Dachman AH, McGehee JA, Beam TE, Burris JA, Powell DA. US-guided percutaneous laser ablation of liver tissue in a chronic pig model. Radiology 1990; 176:129-33

31. Rossi S, Buscarini E, Garbagnati F, et al. Percutaneous treatment of small hepatic tumors by an expandable RF needle electrode. AJR 1998; 170:1015-1022

32. Seki $T$, Wakabayashi $M$, Nakagawa $T$, et al. Ultrasonically guided percutaneous microwave coagulation therapy for small hepatocellular carcinoma. Cancer 1994; 74:817-825

33. Solbiati L, Ierace T, Goldberg SN, et al. Percutaneous US-guided RF tissue ablation of liver metastases: long-term follow up. Radiology 1997; 202:195-203

34. Amin Z, Brown SG, Lees WR. Liver tumor ablation by intersitial laser photocoagulation: Review of experimental and clinical studies. Semin Int Radiol $1993 ; 10: 88-100$

35. Goldberg SN, Gazelle GS, Dawson SL, Mueller PR, Rittman WJ and Rosenthal DI. Radiofrequency tissue ablation using multiprobe arrays: Greater tissue destruction than multiple probes operating alone. Acad Radiol 1995; 2:670-674 
36. Amin Z, Donald JJ, Masters A, et al. Hepatic metastases: interstitial laser photocoagulation with real-time US monitoring and dynamic CT evaluation of treatment. Radiology 1993; 187:339-347

37. Siperstein AE, Rogers SJ, Hansen PD, Gitomirsky A. Laparoscopic thermal ablation of hepatic neuroendocrine tumor metastases. Surgery 1997; 122:1147-1155

38. Curley SA, Izzo F, Delrio $P$, et al. Radiofrequency ablation of unresectable primary and metastatic hepatic malignancies: results in 123 patients. Ann Surg 1999; 230:1-8

39. Leveen RF. Laser hyperthermia and radiofrequency ablation of hepatic lesions. Semin Interv Radiol. 1997; 14:313-324

40. Goldberg SN, Gazelle GS, Solbiati L, Rittman WJ, Mueller PR. Radiofrequency tissue ablation: Increased lesion diameter with a perfusion electrode. Acad Radiol 1996; 3:636-644

41. Yeh MM, Trembly BS, Douple EB, et al. Theoretical and experimental analysis of air cooling for intracavitary microwave hyperthermia applicators. IEEE Trans Biomed Eng 1994; 41:874-82

42. Vogl TJ, Mack MG, Roggan A., et al. Internally cooled power laser for MR-guided interstitial laser-induced thermotherapy of liver lesions: initial clinical results. Radiology 1998; 209:381-5

43. Deardorff DL, Diederich CJ, Nau WH. Ultrasound Applicators with Internal Cooling for Interstitial Thermal Therapy. In: TP Ryan, TZ Wong, eds. Thermal Treatment of Tissue with Image Guidance, Proceedings of SPIE Vol. 3594 Bellingham, WA 1999, pp. 36 - 46

44. Goldberg SN, Stein M, Gazelle GS, Sheiman RG, Kruskal JB, and Clouse ME. Percutaneous radiofrequency tissue ablation: Optimization of pulsed-RF technique to increase coagulation necrosis. JVIR 1999; 10:907-916

45. Nishioka NS, Domankevitz Y, Flotte TJ, Anderson RR. Ablation of rabbit liver, stomach and colon with a pulsed holmium laser. Gastroenterol 1989 96:831-837

46. Goldberg SN, Stein M, Gazelle GS, Kruskal J, Clouse ME. Percutaneous RF Tissue Ablation: Optimization of Pulsed-RF Technique to Increase Coagulation Necrosis. JVIR 1999; 10:907-916

47. Livraghi T, Goldberg SN, Monti F, et al. Saline-enhanced radiofrequency tissue ablation in the treatment of liver metastases. Radiology 1997; 202:205-10

48. Hoey MF, Paul S, Nakib NA. Saline spread and conductivity of the liquid electrode in the liver for radiofrequency energy application. Radiology 1998; 209(P)448

49. Merkle E, Goldberg SN, Lewin JS. Effect of supraparamagnetic MR contrast agents on radiofrequency ablation. Radiology 1999; (in press)

50. Livraghi T, Goldberg SN, Meloni F, Solbiati L, Gazelle GS. Hepatocellular carcinoma: comparison of efficacy between percutaneous ethanol instillation and radiofrequency. Radiology 1999; 210:655-663

51. Dupuy DE, Goldberg SN, Gazelle GS, Rqsenthal DI. Cooled-tip radiofrequency ablation in the vertebral body: temperature distribution in the spinal canal. Radiology 1997; 807:(P)330

52. Goldberg SN, Hahn PF, Tanabe KK, et al. Percutaneous radiofrequency tissue ablation: Does perfusion-mediated tissue cooling limit coagulation necrosis? JVIR 1998; 9:101-111

53. Goldberg SN, Hahn PF, Halpern E, Fogle R, Gazelle GS. Radiofrequency Tissue Ablation: Effect of Pharmacologic Modulation of Blood Flow on Coagulation Diameter. Radiology 1998; 209:761-769 
54. Patterson EJ, Scudamore CH, Owen DA, Nagy AG, Buczkowski AK.

Radiofrequency ablation of porcine liver in vivo: effects of blood flow and treatment time on lesion size. Ann Surg 1998; 227:559-565

55. Heisterkamp J, van Hillegersberg R, Mulder PG, Sinofsky EL, Ijzermans JN. Importance of eliminating portal flow to produce large intrahepatic lesions with interstitial laser coagulation Br J Surg 1997; 84:1245-1248

56. Ryan TP, Goldberg SN. Comparison of simulation and experimental results for RF thermal treatment devices with or without cooling. Proc SPIE $19993594: 14-25$

57. Murakami T, Shibata T, Ishida T, et al. Percutaneous microwave hepatic tumor coagulation with segmental hepatic blood flow occulsion in seven patients. AJR $1999 ; 172: 637-640$

58. Solbiati L, Goldberg SN, Ierace T, Livraghi T, Sironi S, Gazelle GS. Hepatic metastases: percutaneous radio-frequency ablation with cooled- tip electrodes. Radiology 1997; 205:367-374

59. Goldberg SN, Gazelle GS, Solbiati L, Livraghi T, Tanabe KK, Hahn PF, Mueller PR. Percutaneous radiofrequency liver tumor ablation. AJR 1998; 170:1023-1028

60. Malone DE, Lesiuk L, Brady AP, Wyman DR, Wilson BC. Hepatic interstitial laser photocoagulation: demonstration and possible clinical importance of intravascular gas. Radiology 1994; 193:233-7

61. Goldberg SN, Walovitch R, Halpem EF, Gazelle GS. Immediate detection of radiofrequency induced coagulation necrosis using an ultrasound contrast agent. Radiology 1999 (in press)

62. Bartolozzi C, Lencioni R, Ricci P, Paolicchi A, Rossi P, Passariello R. Hepatocellular carcinoma treatment with percutaneous ethanol injection: evaluation with contrast-enhanced color Doppler US. Radiology 1998; 209:387-393

63. Amin Z, Thurrell W, Spencer GM, Harries SA, Grant WE, Bown SG, Lees WR. Computed tomography-pathologic assessment of laser-induced necrosis in rat liver. Invest Radiol 1993; 28:1148-54

64. Mitsuzaki K, Yamashita Y, Nishiharu T, et al. CT appearance of hepatic tumors after microwave coagulation therapy. AJR 1998;171:1397-403

65. Lee FT Jr, Chosy SG, Littrup PJ, Warner TF, Kuhlman JE, Mahvi DM. CTmonitored percutaneous cryoablation in a pig liver model: pilot study. Radiology 1999; 211:687-92

66. Hyodoh $\mathrm{H}$, Hyodoh $\mathrm{K}$, Takahashi $\mathrm{K}$, et al. Microwave coagulation therapy on hepatomas: CT and MR appearance after therapy. JMRI 1998; 8:451-458

67. Boaz, TL, Lewin, JS, Chung, YC, Duerk, JL. MR monitoring of MR-guided radiofrequency thermal ablation of normal liver in an animal model. J Magn Reson Imaging 1998; 8:64-69

68. Diederich, CJ, Nau WH, Deardorff DL, et al. Prostate Thermal Therapy With Interstitial And Transurethral Ultrasound Applicators: A Feasibility Study. In: Thomas P. Ryan, ed. Surgical Applications of Energy, Proceedings of SPIE Vol. 3249 Bellingham, WA 1998, pp. 2 - 13

69. Mueller-Lisse UG, Thoma M, Faber S, et al. Coagulative interstitial laser-induced thermotherapy of benign prostatic hyperplasia: online imaging with a T2-weighted fast spin-echo MR sequence-experience in six patients. Radiology 1999; 210:373379.

70. Steiner P, Botnar R, Goldberg SN, Gazelle GS, Debatin JF. Monitoring of radiofrequency tissue ablation in an interventional MR environment: preliminary ex vivo and in vivo results. Invest Radiol 1997; 32:671-8 
Matching the Energy Source to the Clinical Need / 323

71. Busse H, Rassek M, Grust A, Kahn T, Schwarzmaier HJ. Improved quatitative MR thermometry using a $1.5 \mathrm{~T}$ scanner to monitor cooled applicator systems during laser-induced interstitial thermotherapy. In: TP Ry an, TZ Wong, eds. Thermal Treatment of Tissue with Image Guidance, Proceedings of SPIE Vol. 3594 Bellingham, WA 1999, pp. 196 - 203

72. Samulski TV, Jones E, Henke F, Buffalo C, Scott T, MacFall JM. Magnetic Resonance Image guided. Thermal Therapy With A Radiofrequency Phased Array. In: TP Ry an, TZ Wong, eds. Thermal Treatment of Tissue with Image Guidance, Proceedings of SPIE Vol. 3594 Bellingham, WA 1999, pp. 124 - 128

73. Zhang Q, Chung YC, Lewin JS, Duerk, Л. A method for simultaneous RF ablation and MRI. JMRI 1998; 8:110-114

74. Solbiati L, Goldberg SN, Ierace T, DellaNoce M, Livraghi T, Gazelle GS. Microbubble ultrasound contrast agents: A useful adjunct for radiofrequency tumor ablation. Radiology 1999; (in press)

75. Dawson, SL, Mueller, PR, Lee, MJ, Boland, GW, Goldberg, MA, Fischman, AJ. Value of PET Imaging in Evaluation of Percutaneous Ablation of Malignant Hepatic Neoplasms. Radiology 1994; 193(P) 582:221

76. Goldberg SN, Fogle R, Solbiati L, Gazelle GS. Radiofrequency (RF) Tissue Ablation: Importance of Proper System Grounding. Radiology 1998; 209: 322 (abst.)

77. Rossi S, DiStasi M, Buscarini E, Quaretti P, Garbagnati F, Squassante L, Paties CT, Silverman DE, and Buscarini L. Percutaneous RF interstitial thermal ablation in the treatment of hepatic cancer. AJR 1996; 167:759-768

78. Solbiati L, Goldberg SN, Tiziana I, Livrahgi T, Dellanoce M, Gazelle GS. RF Ablation of Colorectal Metastases: Does three year survival approach that of surgical resection? Radiology 1999 213:122 (abstract)

79. Jiao LR, Hansen PD, Havlik R, Mitry RR, Pignatelli M, Habib N. Clinical shortterm results of radiofrequency ablation in primary and secondary liver tumors. Am J Surg 1999;177:303-6

80. Vogl TJ, Muller PK, Hammerstingl R, et al. Malignant liver tumors treated with MR imaging-guided laser-induced thermotherapy: technique and prospective results. Radiology 1995; 196:257-265

81. Yu YQ. High-power nd:yag laser in the treatment of liver cancer:experimental study and clinical application. In: Subclinical Hepatocellular Carcinoma. Tang ZY, ed. New York, Springer-Verlag, 1984; pp. 120-3

82. Fleisher D. Endoscopic laser therapy for gastrointestinal neoplasms. Surg Clin N Amer 1984; 61:947-953

83. Nolsoe CP, Torp-Pedersen $\mathrm{S}, \mathrm{Holm} \mathrm{HH}$, et al. Ultrasonically guided interstitial NdYAG laser diffuser tip hyperthermia: an in vitro study. Scand J Urol Nephrol Suppl 1991; 137:119-24

84. Amin Z, Donald JJ, Masters A, et al. Hepatic metastases: interstitial laser photocoagulation with real- time US monitoring and dynamic CT evaluation of treatment. Radiology 1993; 187:339-47

85. Hahl J, Haapiainen R, Ovaska J, Puolakkainen P, Schroder T. Laser-induced hyperthermia in the treatment of liver tumors. Lasers Surg Med 1990; 10: 319-21

86. Masters A, Steger AC, Lees WR, Walmsley K, Bown SG. Interstitial laser hyperthermia (ilh) for liver cancer: early clinical experience. Br J Cancer 1990; 62(Suppl 11): 15 
87. Masters A, Steger AC, Lees WR, Walmsley KM, Brown SG. Interstitial laser hyperthermia: a new approach for treating liver metastases. Br J Cancer 1992; 66: 518-22

88. Amin Z, Bown SG, Lees WR. Local treatment of colorectal liver metastases: a comparison of interstitial laser photocoagulation (ILP) and percutaneous alcohol injection (PAI). Clin Radiol 1993; 48: 166-71

89. Nolsoe CP, Torp-Pedersen S, Andersen PH, Karstrup S, Lorentzen T, Holm HH. Ultrasound-guided percutaneous Nd:YAG laser diffuser tip hyperthermia of liver metastases. Semin Int Rad 1993; 10:113-124

90. King RWP, Shen LC, Wu TT. Embedded insulated antenna for communication and heating. Electromagnetics 1981; 1:51-72

91. Foster KR and Schepps Л. Dielectric properties of tumor and normal tissues at radio through microwave frequencies. J Microwave Power 1981; 16:107-119

92. Moriyama E, Matsumi N, Shiraishi T, Tamiya T, Satoh T, Matsumoto K, Furuta T, Nishimoto A. Hyperthermia for brain tumors: improved delivery with a new cooling system. Neurosurgery 1988; 23:189-95

93. Saitsu H, Mada Y, Taniwaki S, Okuda K, Nakayama T, Oishi K, Yoshida K. Investigation of microwave coagulo-necrotic therapy for 21 patients with small hepatocellular carcinoma less than $5 \mathrm{~cm}$ in diameter. Nippon Geka Gakkai Zasshi 1993; 94:359-65

94. Saitsu H, Nakay ama T. Microwave coagulo-necrotic therapy for hepatocellular carcinoma. Nippon Rinsho 1993; 51:1102-7.

95. Watanabe Y, Sato M, Abe Y, Horiuchi S, Kito K, Kimura K, Kimura S. Laparoscopic microwave coagulo-necrotic therapy for hepatocellular carcinoma: a feasible study of an alternative option for poor-risk patients. J Laparoendosc Surg 1995; 5:169-75

96. Sato M, Watanabe Y, Ueda S, Iseki S, Abe Y, Sato N, Kimura S, Okubo K, Onji M. Microwave coagulation therapy for hepatocellular carcinoma. Gastroenterology 1996; 110:1507-14

97. Ryan TP. Comparison of six microwave antennas for hyperthermia treatment of cancer: SAR results for single antennas and arrays. Int J Rad Onc Biol Phy 1991; 21:403-413

98. Hamazoe R, Hirooka Y, Ohtani S, Katoh T, Kaibara N. Intraoperative microwave tissue coagulation as treatment for patients with nonresectable hepatocellular carcinoma. Cancer 1995; 75:794-800

99. Seki T, Wakabayashi M, Nakagawa T, Itho T, Shiro T, Kunieda K, Sato M, Uchiyama $\mathrm{S}$, Inoue $\mathrm{K}$. Ultrasonically guided percutaneous microwave coagulation therapy for small hepatocellular carcinoma. Cancer 1994; 74: 817-25

100. Murakami R, Yoshimatsu S, Yamashita Y, Matsukawa T, Takahashi M, Sagara K. Treatment of hepatocellular carcinoma: value of percutaneous microwave coagulation. AJR 1995; 164:1159-64

101. Seki T, Wakabayashi M, Nakagawa T, et al. Percutaneous microwave coagulation therapy for solitary metastatic liver tumors from colorectal cancer: a pilot clinical study Am J Gastroenterol 1999; 94:322-7

102. Seki T, Wakabayashi M, Nakagawa T, Imamura M, Tamai T, Nishimura A, Yamashiki N, Okamura A, Inoue K. Percutaneous microwave coagulation therapy for patients with small hepatocellular carcinoma: comparison with percutaneous ethanol injection therapy. Cancer 1999; 85:1694-702 
103. Matsukawa T, Yamashita Y, Arakawa A, Nishiharu T, Urata J, Murakami R, Takahashi M, Yoshimatsu S. Percutaneous microwave coagulation therapy in liver tumors. A 3-year experience. Acta Radiol 1997; 38: 410-5

104. Shimada S, Hirota M, Beppu T, Matsuda T, Hayashi N, Tashima S, Takai E, Yamaguchi K, Inoue K, Ogawa M. Complications and management of microwave coagulation therapy for primary and metastatic liver tumors.Surg Today 1998; 28:1130-7

105. Kane RA. Ultrasound-guided hepatic cryosurgery for tumor ablation. Semin Int $\operatorname{Rad} 1993 ; 10: 132-142$

106. Rivoire ML, Voiglio EJ, Kaemmerlen P, Molina G, Treilleux I, Finzy J, Delay E, Gory F. Hepatic cryosurgery precision: evaluation of ultrasonography, thermometry, and impedancemetry in a pig model. J Surg Oncol 1996; 61:242-8

107. Cooper, IS. Cryogenic surgery. NEJM 1963; 268:743-749.

108. Brown NJ, Bayjoo P, Reed MW. Effect of cryosurgery on liver blood flow. Br J Cancer 1993; 68:10-12

109. Ravikumar TS, Steele G Jr, Kane R, King V. Experimental and clinical observations on hepatic cryosurgery for colorectal metastases. Cancer Res 1991; 51:6323-7

110. Stewart GJ, Preketes A, Horton M, Ross WB, Morris DL. Hepatic cryotherapy: double-freeze cycles achieve greater hepatocellular injury in man. Cryobiology $1995 ; 32: 215-9$

111.Lam CM, Shimi SM, Cuschieri A. Ultrasonographic characterization of hepatic cryolesions. An ex vivo study. Arch Surg 1995; 130:1068-72

112. Reiser M, Drukier AK, Ultsch B, Feuerbach S. The use of CT in monitoring cryosurgery. Eur J Radiol 1983; 3:123-8

113. Matsumoto R, Selig AM, Colucci VM, Jolesz FA. MR monitoring during cryotherapy in the liver: predictability of histologic outcome. JMRI 1993; 3: 770-6

114. McLoughlin RF, Saliken JF, McKinnon G, Wiseman D, Temple W. CT of the liver after cryotherapy of hepatic metastases: imaging findings. AJR 1995; 165:329-32

115. Kuszyk BS, Choti MA, Urban BA, Chambers TP, Bluemke DA, Sitzmann JV, Fishman EK. Hepatic tumors treated by cryosurgery: normal CT appearance. AJR $1996 ; 166: 363-8$

116.Preketes AP, King J, Caplehorn JR, Clingan PR, Ross WB, Morris DL. CEA reduction after cryotherapy for liver metastases from colon cancer predicts survival. Aust N Z J Surg 1994; 64:612-4

117.Zhou XD, Tang ZY, Yu YQ. Cryosurgery for hepatocellular carcinoma experimental and clinical study. In: Subclinical Hepatocellular Carcinoma. Tang ZY, ed. New York, Springer-Verlag, 1984. 107-19

118.Zhou XD, Tang ZY, Yu YQ, Weng JM, Ma ZC, Zhang BH, Zheng YX. The role of cryosurgery in the treatment of hepatic cancer: a report of 113 cases. J Cancer Res Clin Oncol 1993; 120:100-2

119.Zhou XD, Tang ZY, Yu YQ, Ma ZC. Clinical evaluation of cryosurgery in the treatment of primary liver cancer. Report of 60 cases. Cancer 1988; 61:1889-92

120. Ravikumar TS, Kane R, Cady B, Jenkins R, Clouse M, Steele G Jr. A 5-year study of cryosurgery in the treatment of liver tumors. Arch Surg 1991; 126:1520-3

121. Preketes AP, Ross WB, Clingan PR, Phadke K, Morris DL. Regional hepatic chemotherapy enhances survival after cryotherapy for liver metastases from colorectal cancer. Proc Annu Meet Am Soc Clin Oncol 1994 13:A599 
122.Cuschieri A, Crosthwaite G, Shimi S, Pietrabissa A, Joypaul V, Tair I, Naziri W. Hepatic cryotherapy for liver tumors. Development and clinical evaluation of a highefficiency insulated multineedle probe system for open and laparoscopic use. Surg Endosc 1995; 9:483-9

123. Weaver ML, Atkinson D, Zemel R. Hepatic cryosurgery in treating colorectal metastases. Cancer 1995; 76:210-4

124. Onik G, Gilbert J, Hoddick W, Filly R, Callen P, Rubinsky B, Farrel L. Sonographic monitoring of hepatic cryosurgery in an experimental animal model. AJR 1985; 144:1043-7

125.Kirgan DM, Guenther JM, Foshag LJ, Grabie M, Ramming KP. Cryosurgical ablation of liver metastases. Proc Annu Meet Am Assoc Cancer Res 1994; 35:A1479

126. Shafir M, Shapiro R, Sung M, Warner R, Sicular A, Klipfel A. Cryoablation of unresectable malignant liver tumors. Am J Surg 1996; 171: 27-31

127.Korpan NN. Hepatic cryosurgery for liver metastases. Long-term follow-up. Ann Surg 1997; 225:193-201

128. Yang R, Sanghvi NT, Rescorla FJ, Kopecky KK, Grosfeld J. Liver cancer ablation with extracorporeal high-intensity focused ultrasound. Eur Urol 1993; $23 \mathrm{Suppl}$ $1: 17-22$

129. Sanghvi NT, Hawes RH. High-intensity focused ultrasound. Gastrointest Endosc Clin N Am 1994; 4:383-95

130. Reilly CR, Yang R, Reilly WM, et al. Tissue heating measurements during high intensity focused ultrasound cancer therapy. J Ultrasound Med 1991: 10:S26.

131. Hill CR, ter Haar GR. High intensity focused ultrasound--potential for cancer treatment. Br J Radiol 1995; 68:1296-1303

132. Cline HE, Hynynen K, Watkins RD, et al. Focused US system for MR imagingguided tumor ablation. Radiology 1995; 194:731-737

133. Moore WE, Lopez RM, Matthews DE, et al. Evaluation of high-intensity therapeutic ultrasound irradiation in the treatment of experimental hepatoma. J Pediatr Surg $1989 ; 24: 30-3$

134. Yang R, Reilly CR, Rescorla FJ, Faught PR, Sanghvi NT, Fry FJ, Franklin TD Jr, Lumeng L, Grosfeld $\mathrm{J}$. High-intensity focused ultrasound in the treatment of experimental liver cancer. Arch Surg 1991; 126:1002-9

135. Deardorff DL, Diederich CJ. Angular directivity of thermal coagulation using aircooled direct-coupled interstitial ultrasound applicators. Ultrasound Med Biol 1999; 25:609-22

Correspondence: Email: sgoldber@caregroup.harvard.edu; Tel. (617)-667-4512; Fax: (617) 667 - 8212 